\title{
EDITORIAL
}

\section{España y Cataluña: la reconstrucción de un pacto}

\author{
Consejo de Redacción
}

Resumen: En este editorial queremos pronunciarnos y proponer la construcción de un discurso integrador. Para ello intentamos explicar los procesos históricos y jurídicos en su complejidad y sus razones internas, presentando con honestidad las posiciones diferentes para así comprenderlas. Creemos que éste puede ser un servicio a nuestros lectores.

En primer lugar abordamos dos perspectivas sobre la cuestión catalana: la histórica y la jurídica. A partir de ambas llegamos a una primera conclusión: ni la historia ni el derecho pueden resolver una cuestión que, con el paso del tiempo, no ha hecho otra cosa sino complicarse, especialmente en los últimos años, aunque ambas perspectivas ofrezcan alguna luz, pues aportan claves de comprensión. Realmente estamos convencidos de que ni una ni otra sirven por sí solas para resolver la cuestión. Sólo un pacto político puede orientar y posibilitar una solución estable. A fin de cuentas, articular un pacto político es también resultado de una historia y se ordena jurídicamente, pero supera ambas perspectivas pues requiere capacidad y voluntad de crear las condiciones para fundar una nueva relación entre España y Cataluña.

A continuación hacemos nuestra propuesta explícita: para avanzar en una nueva resolución sobre la cuestión catalana nos hace falta, como sociedad compleja y plural, reconstruir una nueva relación y fundar un nuevo pacto político a partir de un consenso social y cultural de carácter prepolítico (es decir emocional, moral-axiológico e ideológico) que sirva de base al pacto político, tanto entre los ciudadanos de Cataluña como entre éstos y los ciudadanos del conjunto de España. En la perspectiva de una Europa fuerte, unida, coherente y estable en la que las asimetrías federales no deben impedir avanzar en una unidad cada vez mayor, también podemos pensar una España capaz de integrar en lo común lo que es diferente. La solidaridad y la igualdad entre todos los ciudadanos españoles deben incluir el reconocimiento de lo diferencial, de la España plural y diversa a partir de la unión que se expresa por medio del pacto federal. El reconocimiento de la singularidad no se logra sólo y necesariamente por la bilateralidad en las relaciones, que es tan sólo una fórmula posible entre otras. Proponemos pues un nuevo pacto político entre los ciudadanos, que, llegado el día, pueda ser sometido a un referéndum de revisión constitucional en el que 
participen todos los españoles. Este pacto será posible si entre todos alcanzamos un discurso integrador. Es nuestra propuesta.

Palabras clave: cuestión catalana, derecho a decidir, Estado compuesto, pacto federal, pacto prepolítico, relación entre España y Cataluña, relación pacticia, revisión constitucional, sentencia del tribunal constitucional sobre el Estatuto de Cataluña.

\section{Spain and Catalonia, rebuilding a Pact}

\section{Editorial Board}

Abstract: In this editorial commentary, we want to express our opinion and propose the construction of an inclusive discourse. So we try to explain the historical and legal processes in their complexity and its internal reasons, presenting the different positions to understand them with honesty. We believe that this can be a service to our readers.

First addressed two perspectives on the Catalan issue: the historical and the legal question. From both came to a first conclusion: neither the history nor the right can resolve an issue that, over time, has not done anything else but get complicated, especially in recent years, although both perspectives offer some light, because they provide keys to understanding. We are really convinced that neither serve on their own to resolve the issue. Only a political Pact can guide and facilitate a stable solution. After all, articulate a political Pact is also the result of a history and is ordered legally, but exceeds both perspectives as requires capacity and will of create then conditions for found a new relationship between Spain and Catalonia.

Then we make our explicit proposal: to advance in a new resolution on the Catalan issue we need, as a complex and plural

\section{L'Espagne et la Catalogne: la recons- truction d'un pacte}

\section{Comité de rédaction}

Résumé: Dans cet éditorial nous voulons nous prononcer et proposer la construction d'un discours inclusif. Pour cela, nous essayons d'expliquer les processus historiques et juridiques dans leur complexité et leurs raisons internes, en présentant avec honnêteté les différentes positions et ainsi, essayer de les comprendre. Nous pensons que cela peut rendre service à nos lecteurs.

D'abord nous abordons la problématique catalane depuis deux perspectives: la perspective historique et la perspective juridique. À partir de cela, nous arrivons à une première conclusion : ni l'histoire ni le droit peuvent résoudre une problématique qui, avec le temps, $\mathrm{n}^{\prime}$ a fait que se compliquer, surtout dans les dernières années. Malgré cela, les deux perspectives nous apportent un peu de lumière sur la question, surtout au niveau de la compréhension. Nous sommes réellement convaincus que ni l'une ni l'autre servent d'elles mêmes à résoudre le problème. Seul un pacte politique peut orienter et permettre une solution stable. Tout compte fait, articuler un pacte politique est aussi le résultat d'une histoire et s'organise juridiquement, tout en dépassant les deux perspectives, puisqu'il requiert $d$ 'une capacité et $d$ 'une volonté de créer les conditions pour fonder une nouvelle relation entre l'Espagne et la Catalogne. 
society, rebuild a new relationship and to found a new political Pact from social and cultural consensus of pre-political character (i.e. emotional, moral-axiological and ideological) serving as to base for the political Pact, both among the citizens of Catalonia and between them and the citizens of the whole of Spain.

In the perspective of a strong, united, coherent and stable Europe in which federal asymmetries should not hinder progress in a growing unit, we could also think a Spain able to integrate the common which is different. Solidarity and equality among all Spanish citizens must include recognition of the differential, the plural and diverse Spain from marriage that is expressed through the federal Pact.

The recognition of the singularity is accomplished only and necessarily by the bilateralism in the relations, which is only one possible formula among others. We therefore propose a new political Pact between the citizens, who arrived the day, it can be subjected to a referendum on constitutional revision involving all Spaniards. This Pact will be possible if all we reach an inclusive discourse. It is our proposal.

Keywords: Catalan question, the right to decide, State composed, federal pact, prepolitical covenant relationship between Spain and Catalonia, pacticia relationship, constitutional review, the Constitutional Court ruling on the Statute of Catalonia.
Ensuite nous faisons notre proposition explicitement : pour avancer dans une nouvelle résolution sur la problématique catalane, il nous faut, en tant que société complexe et pluraliste, reconstruire une nouvelle relation et fonder un nouveau pacte politique à partir $d^{\prime}$ 'un consensus social et culturel de caractère pré-politique (c'est-à-dire, émotionnel, moral-axiologique et idéologique). Ce consensus sera la base du pacte politique, aussi bien entre les citoyens de la Catalogne qu'entre ces derniers et les citoyens de l'ensemble de l'Espagne.

Dans la perspective d'une Europe forte, unie, cohérente et stable, dans laquelle les asymétries fédérales ne doivent pas empêcher $d^{\prime}$ avancer vers une unité de plus en plus grande, nous pouvons également penser la possibilité d'une Espagne capable d'intégrer ce qui est commun et ce qui est différent. La solidarité et l'égalité entre tous les citoyens espagnols doivent inclure la reconnaissance de la différence, de l'Espagne pluraliste et diverse, articulée à partir de l'union exprimée à travers un pacte fédéral.

La reconnaissance de la singularité ne dépend pas seulement et nécessairement de la bilatéralité, qui n'est qu'une formule possible parmi d'autres. Nous proposons donc un nouveau pacte politique entre citoyens qui, le moment venu, puisse être soumis à un référendum de révision constitutionnelle et dans lequel pourrons participer tous les citoyens espagnols. Ce pacte sera possible si, entre tous, nous trouvons un discours inclusif. C'est notre proposition.

Mots clés: problématique catalane, droit de décider, État composé, pacte fédéral, pacte prépolitique, relation entre l'Espagne et la Catalogne, révision constitutionnelle, sentence du tribunal constitutionnel sur le Statut d'Autonomie de la Catalogne. 
Fecha de aprobación: 21 de abril de 2016.

Diverses són les parles $i$ diversos els homes, $i$ convindran molts noms a un sol amor (Salvador Espriu)'.

En la coyuntura que atravesamos en Europa, todo lo que une, refuerza y todo lo que divide, debilita. Y Europa necesita más que nunca la fuerza, la unidad y la coherencia. Como socios y vecinos, deseamos una España fuerte y estable (Manuel Valls, primer ministro de Francia) ${ }^{2}$.

Quisiera advertir a los caballeros de la City [...que] a menos que abracen la sabiduría a tiempo, el sistema sobre el que viven se pondrá tan enfermo que se verán inundados por cosas insoportables que odiarán mucho más que los remedios suaves y limitados que se les ofrecen (John M. Keynes) ${ }^{3}$.

\section{Introducción ${ }^{4}$}

La madurez y solidez de una sociedad se refleja en su capacidad para afrontar problemas decisivos, sabiendo detectarlos certeramente, definirlos y después jerarquizarlos y priorizar aquellos más importantes e inaplazables. A partir de este momento se puede acometer su solución.

Nos parece que hay un problema, al que en este texto nos referiremos convencionalmente como cuestión catalana, que afecta esencialmente a la convivencia y a la dinámica política no sólo de Cataluña, sino también de España en su conjunto 5 .

' La pell de brau, XXX.

${ }^{2}$ El País, 23-7-2014.

3 J. M. KeYNes (1931) The Collected Writings [of John Maynard Keynes (XIX)], Nueva York, Royal Economic Society (citado por J.J. López BuRniol, en "Prólogo" a Á. Ossorio y Gallardo (2015) Contra el dinerismo, Madrid, Reus, 16-17).

${ }^{4}$ El editorial, como siempre, es el resultado de la reflexión y el diálogo entre los miembros del Consejo de redacción que se ha desarrollado en las siguientes sesiones de trabajo: 20-I-2016, 11-II-2016, 9-III-2016 y 19-IV-2016, y sólo compromete al Consejo. En este caso no ha habido la participación de ningún ponente externo.

${ }^{5}$ En este comentario, siendo conscientes de que a veces la terminología es vacilante y puede ser ambigua, usaremos los términos Cataluña y España de la siguiente manera: Cataluña servirá tanto para designar 
En este momento, la cuestión nos parece importante aunque ni es la única ni la más decisiva. En nuestro mundo existen, sin duda, un conjunto de problemas a priorizar: la violencia terrorista que afecta de lleno a Europa, el cambio climático y la crisis ecológica, los refugiados del Mediterráneo, pero sobre todo la pobreza y las crecientes desigualdades tanto mundiales, como las internas en cada sociedad, generadoras todas a su vez de más pobreza. Éstas, al menos, son cuestiones esenciales de las que no podemos desentendernos fácilmente, de una enorme complejidad y que requieren un esfuerzo colectivo de grandes dimensiones. Al lado de estas cuestiones, la cuestión catalana no parece que esté entre las decisivas para nuestro mundo.

Dirigiendo la mirada al contexto más inmediato, podríamos decir que también en la España de hoy subrayaríamos al menos cuatro grandes bloques de cuestiones o preocupaciones a priorizar y resolver: el refuerzo del europeísmo como clave de solución de las crisis, aunque el actual escenario europeo sea también parte de la crisis, y en esta perspectiva la consolidación de la Economía social de mercado (Soziale Marktwirtschaff) que establece el Tratado de Lisboa'; una recuperación económica que garantice estabilidad y crecimiento, aunque ciertamente se oriente con decisión a la integración social de los excluidos y los jóvenes, a una solidaridad interregional auténtica y realista, y al desarrollo de políticas públicas sociales acordes con las necesidades de la mayoría de la población y de una justa comprensión del bien común ${ }^{7}$; la regeneración democrática, la lucha contra la corrupción sistémica y la promoción de un auténtico pacto social y político que garantice todo el sistema

una región geográfica como una comunidad autónoma que es parte de un nivel de la administración estatal de España y, como tal, tiene una configuración jurídica constitucional precisa. Por otra parte Cataluña también es una comunidad nacional con fuerte personalidad histórica que ciertamente se ha configurado a lo largo de su historia de formas distintas desde un punto de vista jurídico-institucional y en su relación con el conjunto del espacio ibérico. España, es decir el Reino de España, es país, una nación, un Estado soberano, miembro de pleno derecho de la comunidad de estados, miembro de la ONU y parte de la Unión Europea. Cataluña la entendemos como un sujeto histórico e institucional y como una comunidad, parte de España. Este uso no deforma, a nuestro juicio, la posible variedad de fórmulas de relación de Cataluña, parte de España, con España en cuanto Estado en el que existen 17 Comunidades y 2 ciudades autónomas y que es parte de la Unión Europea, integrada en este momento por 28 estados. No contraponemos Cataluña a España como si una excluyera a otra como sujetos políticos diferentes, pero tampoco presuponemos una única fórmula de relación de Cataluña con España, a la que a veces nos referimos como el resto de España o como el conjunto de España.

${ }^{6}$ Cfr. nuestro editorial: "Un sistema de Economía social de mercado para una Europa solidaria, responsable y productiva": RFS 67 (2012) 5-29.

7 Cfr. nuestro editorial: "Política económica del Gobierno de España 2011-2015. Estabilidad lograda, fractura persistente": RFS 70 (2015) 373-396. 
que nos ha permitido disfrutar de un período de paz, ${ }^{8}$ prosperidad y desarrollo humano y social sin precedentes en nuestra época contemporánea9; por último, está la cuestión catalana, a la que dedicamos este editorial.

¿Por qué, pues, creemos que tiene importancia dicha cuestión? La relación problemática de Cataluña con el conjunto de España no es una cuestión nueva. Al menos desde la segunda mitad del siglo XIX la cuestión catalana viene planteándose en el centro del tablero social, político e institucional español. Como hemos comprobado recientemente, las dinámicas políticas existentes en el espacio español y en el espacio catalán con frecuencia se condicionan mutuamente, de una manera que podríamos llamar estructural o persistente.

Por un lado, la economía hace que ambos espacios estén intrínsecamente relacionados: en 2013, por ejemplo, Cataluña vendió en bienes y servicios al resto de España lo equivalente a 44.000 millones de euros, el $30 \%$ de su producción, más de lo que vendió fuera de España, y viceversa, en el mercado catalán, los bienes y servicios consumidos hasta un total de 25.500 millones de euros proceden de otras regiones españolas; el superávit comercial entre Cataluña y el resto de España es 18.500 millones de euros y el déficit comercial de Cataluña con el extranjero es de 16.500 millones de euros. De hecho Cataluña es, con diferencia, la comunidad autónoma con un mayor saldo positivo en estos intercambios comerciales interregionales.

Por otro lado, la convivencia y los lazos populares y familiares entre ciudadanos de Cataluña y los de otras regiones españolas son fuertes o muy fuertes. Cataluña tenía 7.565.603 habitantes según el censo de población del año 2012, tras unos años de aumento continuado a causa sobre todo de la inmigración extranjera. Desde 2001 se ha producido un incremento de su población en un millón de personas, hecho que sitúa a Cataluña por encima del promedio español y europeo en la acogida de población extranjera. El aumento demográfico corresponde al millón cercano de extranjeros que actualmente viven en Cataluña (un 18\% de la población). El impacto migratorio ha sido especialmente relevante en el ámbito metropolitano de Barcelona, un área que con cerca de cinco millones de personas concentra más

${ }^{8}$ Con la sola excepción del terrorismo de los GRAPO y de ETA, finalmente derrotados por el Estado de derecho.

${ }^{9}$ Cfr. nuestros editoriales: "Regeneración ética y compromiso político para una sociedad democrática avanzada": RFS 68 (2013) 5-20, y "Crisis económica y derechos sociales irreductibles. Valor de la dignidad humana como criterio para los derechos sociales": RFS 68 (2013) 179-201. 
del $67 \%$ de la población de Cataluña. La última gran oleada migratoria se registró entre los años 1950 y 1975, cuando la población creció casi dos millones y medio de habitantes procedentes de toda España. Actualmente un $64 \%$ de los catalanes ha nacido en Cataluña (4.830.000, datos de 2015) ${ }^{10}$, un $20 \%$ nació en otras comunidades de España (619.000 en Andalucía o 273.000 en ambas Castillas, incluida Madrid) y alrededor de un $15 \%$ es de origen extranjero, inmigrante de la UE o de otros espacios. Por otra parte, fuera de España viven 242.000 nacidos en Cataluña (de ellos unos 80.000 en la UE según datos de 2015, aunque sólo seis años antes eran 144.000). Sólo un $25 \%$ de la población catalana tiene los cuatro abuelos nacidos en Cataluña, lo que equivale a decir que el $75 \%$ de su población es de origen inmigrado, más reciente o en las dos grandes oleadas migratorias del siglo XX (años 20 y años 50 y posteriores); podemos afirmar con bastante certeza que la mayoría de las familias catalanas tienen total o parcialmente sus raíces en otras regiones de España, lo que ayudaría a entender que García, Martínez, López, Sánchez, Rodríguez, Fernández, Pérez, González, Gómez y Ruiz sean actualmente los diez apellidos más frecuentes en Cataluña.

No venimos de culturas tan distintas ni distantes ${ }^{11}$, pues hemos de reconocer que Cataluña se encuentra entre las sociedades más plurales y complejas de nuestro ámbito euro-occidental, una sociedad de mestizaje y de identidades complejas. Ésta va a ser siempre una clave para aproximarnos a la cuestión catalana.

Cuatro razones, pues, hacen que la cuestión catalana sea también una cuestión central española: la política institucional, la dinámica pluralista de confrontación, la balanza comercial-y económica en general-y, por último, la estructura y dinámica demográficas. Cuando la cuestión catalana se torna problemática, o cuando es discutida, es siempre una cuestión central para toda España.

La intención de este editorial es doble. Aparentemente está ya dicho todo o casi todo. En realidad hace falta que nos pronunciemos sin apasionamiento y construyamos un discurso integrador. Por un lado, intentaremos romper "evidencias" que se tienen como tales en algunos ámbitos, explicando los procesos histórico-jurídicos y políticos en su complejidad, dentro de las posibilidades de espacio y del género

\footnotetext{
${ }^{10}$ El porcentaje de nacidos en España para el conjunto del país llega al 86,8\%. Esta diferencia explica uno de los caracteres demográficos y sociológicos que hacen de Cataluña una sociedad con una fuerte componente "mestizo".

11 Grandes hispanistas, e historiadores sobre Cataluña, del siglo XX como Jaume Vicens Vives, Miquel Batllori, Martín de Riquer, John H. Elliott o Pierre Vilar repitieron que no se puede entender la cultura catalana sin la española, ni tampoco ésta sin aquella.
} 
editorial; por otro lado, siendo conscientes de ser sujetos parte de los procesos, intentaremos explicar las razones internas de los mismos buscando presentar con honestidad las diferentes posiciones para así comprenderlas. Creemos que de esta forma ganaremos en calidad de intelección o comprensión, aunque perdamos cierta objetividad que, por otra parte, residiría sólo en una aparente aunque improbable, engañosa e insuficiente distancia analítica.

En este editorial abordamos la cuestión catalana desde dos perspectivas valiosas pero insuficientes: la histórica (parte segunda) y la jurídica (parte tercera), perspectivas a partir de las cuales llegaremos a una primera conclusión: ni la historia ni el derecho pueden, ellos solos, dirimir una cuestión que con el tiempo se ha ido configurando de tal forma que sólo un pacto político puede orientarnos y posibilitar una solución. Afirmamos que tanto la perspectiva histórica como la jurídica aportan claves de comprensión y por eso nos detenemos en ellas, pero también estamos convencidos de que ni una ni otra sirven para resolver la cuestión, aunque sin ellas no es posible articular un pacto político como el que proponemos, que a fin de cuentas es resultado de una historia y se ordena jurídicamente, pero que supera siempre ambas perspectivas.

En realidad la perspectiva histórica, además de su complejidad, se enfrenta a antiguos y a muy recientes procesos de "nacionalización" de la historia en cada comunidad, se trate de los intentos conservadores-populistas, nacional-católicos - liberal-progresistas de "nacionalizar" la historia española, o de los intentos románticos-medievalizantes, católico-populares o republicanos de "nacionalizar" la historia catalana.

Tampoco queremos relativizar ni menospreciar el valor de la ley. Al contrario, sabemos bien que el garantismo jurídico es parte esencial de la democracia, pero desconfiamos de cualquier intento de confiar las posibilidades de solución de un problema político y cultural tan complejo sólo al poder del derecho.

En la cuarta parte propondremos algunos escenarios actuales y a partir de ello, en la parte quinta, haremos explícita nuestra propuesta. Para avanzar en una nueva resolución sobre la cuestión catalana nos hace falta, en cuanto sociedad compleja y plural, reconstruir una nueva relación que integre dos narraciones, articulando lo diferencial en lo común y desarrolle lo general y común a través del reconocimiento de la singularidad. Podemos alcanzar un nuevo pacto basado en un consenso social y cultural de carácter prepolítico que fundamente y acompañe esa propuesta. Se trataría de un pacto tanto entre los ciudadanos de Cataluña, como entre éstos y los ciudadanos del conjunto de España, un pacto que en su día 
permita un acuerdo político sometido a un referéndum de revisión constitucional en el que participen todos los ciudadanos españoles y, entre ellos, obviamente los ciudadanos catalanes. Se trataría de un nuevo pacto constitucional entre todos los españoles y entre España y Cataluña, que a todos correspondería pues a todos afectaría.

\section{La perspectiva histórica}

\section{I. Una relación secular compleja}

Cataluña ha ido construyéndose a lo largo del tiempo con las aportaciones de energías de muchas generaciones, de muchas tradiciones y culturas, que han encontrado en ella una tierra de acogida. Así comienza el preámbulo del vigente Estatuto de Cataluña, que a su vez concluye con sendas afirmaciones: recogiendo el sentimiento y la voluntad de la ciudadanía de Cataluña, [el Parlamento de Cataluña] ha definido de forma ampliamente mayoritaria a Cataluña como nación y la Constitución Española reconoce la realidad nacional de Cataluña.

Desde los comienzos de esa realidad nacional de Cataluña hasta el siglo XIX ha habido una continua sucesión de expresiones de confrontación y de coexistencia pacífica con el conjunto de España. La convivencia ha predominado sobre el enfrentamiento. Es el "tiempo largo" de la historia o dimensión estructural de la misma $^{12}$. De lo que difícilmente se podría hablar, sin embargo, es de una perfecta integración territorial del espacio catalán en el espacio español. ${ }^{13}$ Antes de la formación del Estado liberal en el siglo XIX, hablar de nacionalidades históricas, de soberanías originarias o de Estados independientes parece del todo punto anacrónico. Lo que sucedió después es fruto de la uniformización administrativa y de las políticas educativas, mercantiles y culturales de ese mismo Estado. Ha sido éste el esfuerzo por nacionalizar la historia: la de España, "inventando" una nación española como sujeto histórico de origen remoto, a la que desde la

\footnotetext{
${ }^{12}$ Según la terminología acuñada por F. Braudel y la escuela historiográfica francesa de los Annales.

${ }^{13}$ Recientemente han aparecido algunas síntesis interesantes, entre ellas, la dirigida por G. TORTELLA (2016) Cataluña en España, Madrid, Gadir.
} 
confrontación se contrapuso una nación catalana también "inventada"14. Aunque es cierto que todos los pueblos, especialmente desde el orden configurado tras Westfalia, a mediados del siglo XVII, han ido formándose como tales por medio de los estados, o a partir de conceptos como soberanía y nacionalidad, lo cierto es que esta conformación surgió con fuerza cuando comenzó el predominio de los Estados nacionales, después de la ruptura religiosa provocada por la reforma protestante en Europa occidental y central.

Aunque puede ser una cierta simplificación, los siglos XVII y XVIII vieron nacer los sistemas conceptuales que sustentaban los modernos estados soberanos, y el siglo XIX vio formarse en torno a los mercados los estados liberales como unidades administrativas con una fuerte conciencia e identidad creciente como naciones, aunque éstas fueran muy diferentes en unos y otros espacios europeos. Las decisiones políticas de crear una nación a partir de una lengua común, impuesta desde una escuela unificada en la que se enseñaba sólo una historia patria única, son comunes durante el siglo XIX a otros países o estados europeos. En el Estado liberal, lengua, historia y escuela están intrínsecamente unidas en la nacionalización de un país detrás del Estado para dotarlo de unidad administrativa-política, no sólo mercantil. Éste ha sido un proceso generalizado en la Europa de los Estados liberales después de 1815 hasta, al menos, el final de la segunda guerra mundial. Ni Estado ni nación son realidades ahistóricas, casi metafísicas o bienes morales absolutos, ni tampoco realidades tan contingentes y relativas que deben ser discutidas radicalmente "ex novo" para reiniciar continuamente un nuevo pacto prescindiendo de la configuración histórica y de la ordenación jurídica de estas realidades hasta el presente.

No obstante, en la relación entre los espacios hispanos y sus comunidades ha predominando una cultura del pacto ${ }^{15}$ y de aquella alianza que está en su base.

\footnotetext{
14 Inventada no quiere decir arbitraria o imaginada: las naciones son sistemas de creencias y adhesiones emocionales, resultado de construcciones culturales complejas a lo largo del tiempo, de las que se benefician las diferentes élites que hegemonizan un proceso de construcción o "invención" en el sentido que aquí usamos esa expresión. Desde hace 25 años ha reflexionado e investigado sobre esta cuestión como historiador J. Álvarez Junco (2016) Dioses útiles, Barcelona, Galaxia Gutenberg, así como desde diversas perspectivas antropológicas LI. DUCH (2011) "Consideraciones antropológicas sobre identidad y tradición, a partir del documento episcopal Raíces cristianas de Cataluña (1985)": Revista de Fomento Social 66, 73-85y J. CarRera I CarRera (2015) "¿independencia o independencias?": Razón y Fe 273 [n. 1407], 39-48.
}

${ }^{15}$ Cf J. Vicens Vives (1954) Notícia de Catalunya; vid. cap. 5, sobre el pactismo, o J. Ferrater Mora (1944) Les formes de la vida catalana, Santiago de Chile; vid. caps. 1 a 4: continuidad, "seny", mesura, ironía. Para el tema de la alianza, cf. A. CORTINA ORTs (2001) Alianza y contrato, Madrid, Trotta, 15-21. 
Cataluña ha existido en una permanente relación de convivencia y cooperación con los otros pueblos que han habitado el solar hispano. De hecho durante siglos Cataluña ha sido una tierra de paso entre el espacio hispánico (el Ebro, la Meseta, Levante) y el espacio galo-occitano, así como un corredor para el tránsito peninsular del comercio con el resto de Europa y de recepción cultural mediterránea.

Desde mediados del siglo XII la tendencia catalano-occitana que hasta entonces había estado asentada a un lado y otro de los Pirineos, viró hacia el sur y hacia una confluencia creciente con Castilla en el espacio hispánico. Este giro se consolidó tras la batalla de las Navas de Tolosa (1212) en la que participaron fuerzas militares catalanas y el tratado de Corbeil que zanjaba la renuncia de los condes de Barcelona a sus pretensiones territoriales en Provenza y el sur de Francia. Esta confluencia dos siglos y medio después acabó sentando en las coronas de Castilla (unitaria y centralizadora) y de Aragón (compuesta y confederal) a personas de la misma familia, los Trastámara. El compromiso de Caspe (1412) y la unidad dinástica, suficientemente consolidada a la muerte de Fernando V de Aragón, el Rey Católico (1516), marcaron un siglo XV y primeros decenios del siglo XVI con un intenso proceso de convergencia espacial e institucional, pero no lograron totalmente la constitución de la monarquía hispana de los Austria como Estado unitario, aunque la unión personal dinástica constituyó un hito esencial en el proceso comenzado a principios del siglo XV y que había de culminar a mediados del siglo XIX.

En el mismo momento en que en Europa occidental surgían monarquías nacionales cada vez más fuertes, como Francia, Inglaterra y Escocia, Castilla y la Corona de Aragón, los Países Bajos o Portugal, en la parte central de Europa (Mitteleuropa) el eje germánico-itálico seguía estando dividido en multitud de ciudades-Estado o pequeños Estados y en otras unidades territoriales más o menos autónomas. Sólo la doble corona austro-húngara de los Habsburgo configuraba, al este de Baviera y del Véneto, una monarquía compuesta y confederal semejante en su estructura política a la Corona de Aragón.

Vista en perspectiva, la relación de España con Cataluña a lo largo de siglos no ha sido lineal sino compleja, pues ha ido presentando diferentes formas de articularse. Podemos decir que el actual marco de relaciones comienza, tras la recuperación económica de Cataluña a lo largo del siglo XVIII, con la división provincial promovida en 1833 por Javier de Burgos en el primer gobierno español propiamente liberal-moderado ${ }^{16}$. Tras la Constitución liberal doceañista de Cádiz y el comienzo

16 Ese mismo año se publicó la oda de Bonaventura C. Aribau La Pàtria, que marca el inicio de la
"Renaixença", la recuperación literaria del catalán como lengua poética y más tarde como lengua de 
de la estructuración liberal de una administración y un mercado únicos para toda España, con la división provincial y el proteccionismo comercial interior, hubo que esperar, sin embargo, a finales del siglo XIX para que esta articulación comenzase a hacerse problemática para el centralismo madrileño del bloque aristocráticoagrario-burgués que ocupaba el poder a causa del surgimiento del nacionalismo político catalán, cuya primera expresión sólida podríamos fechar en el asamblea municipalista de Manresa y la aprobación de las conocidas como Bases per a la Constitució Regional Catalana (27-III-1892).

Esta eclosión en el último tercio del siglo XIX coincide con una segunda generación de nacionalismos europeos finiseculares e irredentos que, tras los éxitos de las unificaciones de Alemania e Italia, serían protagonistas de otra oleada de naciones que tras la doctrina Wilson de 1918 y el final de la "gran guerra", conseguirán configurarse como estados, como Checoeslovaquia o Yugoslavia, o en 1922 Irlanda. Las reacciones nacionalistas "españolistas", especialmente las de una parte importante del ejército sucesivamente derrotado en las últimas colonias ultramarinas y en África, y de algunos líderes conservadores durante la dictadura de Primo de Rivera contribuyeron a acrecentar la polarización, muchas veces con una política simplemente represiva realizada por el Estado español, tanto en los aspectos de orden público como en los lingüístico-culturales.

Algunas formas pre-estatales de autogobierno habían existido en los condados catalanes, ciertamente desde el siglo XIII. Desde finales del siglo anterior estas unidades procedentes de la antigua Marca hispánica formaban parte de la confederación de la Corona de Aragón, y se encarnaron en instituciones como la Generalitat y en un ordenamiento jurídico específico, recogido en las "Constitucions i altres drets de Catalunya" y en otras leyes. Tras la derrota de los "austracistas", partidarios de una unión confederal con los otros reinos de España como la existente hasta entonces, la ocupación militar de 1714 de Barcelona y del resto de Cataluña, con la subsiguiente derogación del Derecho público del Principado y la supresión de los fueros catalanes a raíz de los decretos de Nueva planta, fueron varios los intentos de recuperación de formas diversas de autogobierno, entre otros la Mancomunidad de las cuatro Diputaciones provinciales catalanas en 1914 en el marco de la Monarquía constitucional, la "invención" republicana de la Generalitat en abril de 1931, pactada entre Azaña y Macià en el marco de la segunda República española

cultura; los textos esenciales del catalanismo político, no todos nacionalistas, aparecieron cincuenta años después: Lo Catalanisme de V. Almirall (1886), El regionalismo de J. Mañé i Flaquer (1887), La tradició catalana de J. Torras i Bages (1892), La Nacionalitat Catalana de E. Prat de la Riba (1906), Per Catalunya de D. Martí i Julià (1913), Per la concòrdia de F. Cambó (1930) y L'altra concòrdia de J. Bofill i Mates (1930). 
y de su Constitución y consolidada con el Estatuto de 1932 (conocido como Estatut de Núria), y restablecida nuevamente, treinta y ocho años después de su derrota, en la persona del presidente de la institución en el exilio que había conservado y transmitido la legitimidad moral e histórica de autogobierno de Cataluña y fue nombrado por el Rey presidente de la Generalitat de Cataluña tras las elecciones democráticas españolas de junio de 1977.

\subsection{Una historia reciente llena de promesas y de sorpresas}

Actualmente Cataluña es una comunidad autónoma constituida en el marco de la Constitución española de 1978 que reconocía la existencia de una realidad anterior, la que en 1931 había "plebiscitado" un Estatuto de autonomía. Creemos que no debe ni puede ignorarse esta historia de afirmación y respeto de los derechos fundamentales y de las libertades públicas colectivas de un pueblo como el catalán para captar su identidad histórica como comunidad o realidad nacional.

La Constitución de 1978 que dio paso al Estado de las autonomías, fue el marco en el que se inscribió el Estatuto de autonomía de Cataluña, conocido como Estatut de Sau (1979). Éste recogía algunos hechos fundamentales y principios inspiradores que fueron mantenidos como tales en el preámbulo del vigente Estatuto de autonomía de 2006 (también conocido como Estatut de Mirabet): un país rico en territorios y gentes con una gran diversidad, una comunidad de personas libres donde pueden vivir y expresar identidades diversas, un compromiso comunitario basado en el respeto a la dignidad de todas y cada una de las personas, una sociedad integradora, con capacidad superadora de dificultades y conflictos, innovadora y emprendedora, un tradición cívica y asociativa, una siempre reconocida importancia de la lengua y de la cultura catalanas, una participación en la construcción del proyecto político de la Unión Europea, cuyos valores y objetivos Cataluña comparte y finalmente una tradición humanista comprometida con la construcción de un orden mundial pacífico y justo.

Según el Estatuto de 2006, el desarrollo de la personalidad política catalana se realiza y se ha de realizar en el marco de un Estado que reconoce y respeta la diversidad de identidades de los pueblos de España. Cataluña es y ha formado parte de España y de sus diversas institucionalizaciones estatales.

Las relaciones entre Cataluña y el resto de España como espacios y realidades, así como las relaciones entre las formas institucionales jurídico-políticas existentes en Cataluña y el conjunto de España como Estado o como su administración central, 
han sido cambiantes y algunas veces conflictivas, pero han sido una realidad estable en largos períodos en que ha existido un pacto, también en la reciente etapa democrática constitucional.

Desde 1978, la Constitución reconoce la existencia de nacionalidades en España (Constitución española 1978, a partir de ahora CE, art. 2) y reconoce que hay "territorios" que "plebiscitaron" afirmativamente un estatuto de autonomía en otro momento (de hecho, durante la República) y están dotados de regímenes pre-autonómicos con órganos colegiados (CE, disposición transitoria segunda).

Al amparo de la Constitución y de otras leyes y normas derivadas de la misma se desarrolló el gobierno autonómico catalán a partir de 1979, si bien con un reconocimiento preconstitucional entre junio de 1977 de la Assemblea de parlamentaris constituida con los electos para las Cortes generales españolas tras el 15 de junio de 1977.

En este período preconstitucional tuvo un significado no menor el restablecimiento ya aludido de la Generalitat en la persona del presidente de esa institución republicana hasta entonces en el exilio, que fue nombrado al mismo tiempo presidente de la Diputación de Barcelona. El reconocimiento de una institución ajena a la monarquía parlamentaria y previa a la Constitución, cuya legitimidad además derivaba de otra Constitución, la republicana española de 1931 y el subsiguiente Estatuto de autonomía de Cataluña de 1932 (llamado de Núria), y en última instancia, de una filiación histórica difusa que la relacionaba con la medieval institución de la Diputació del General (cuyo origen remonta a 1289 y fue definitivamente configurada como Generalitat en las Cortes celebradas en Cervera en 1359, durante el reinado de Pedro el Ceremonioso), ha hecho que algunos, entre otros uno de los "padres" (ponentes) de la Constitución en 1977-1978, Miguel Herrero y Rodríguez de Miñón, haya interpretado que lo establecido en la Disposición adicional primera de la CE relativa a los derechos históricos de los territorios forales puede referirse también a Cataluña. El Estatuto, vigente desde 2006, afirma que el autogobierno de Cataluña se fundamenta en la Constitución, pero también en los derechos históricos del pueblo catalán que, en el marco de aquélla, dan origen en este Estatuto al reconocimiento de una posición singular ${ }^{17}$ de la Generalitat. Aunque la Sentencia del Tribunal Constitucional (STC) 31/2010 niegue contenido jurídico a ese fundamento, la referencia al derecho histórico parece afirmada con claridad.

\footnotetext{
17 La letra redonda es nuestra.
} 


\subsection{La reciente "renacionalización forzada" de Cataluña}

El hecho de aceptar que Cataluña es una comunidad o una realidad nacional, declaración que es conforme con nuestra Constitución según la interpretación que hizo el Tribunal constitucional (TC, a partir de ahora) en la sentencia de 28-VI-2010 (STC 31/2010, a partir de ahora) no es un resultado artificioso de los procesos de "nacionalización de las masas" que hayan podido adoptarse en uno u otro momento o lugar, sino el reconocimiento de una realidad histórica permanente a lo largo de siglos.

En época más reciente, sin embargo, pensamos que desde los ámbitos educativos y mediáticos y culturales controlados por el poder político catalán se ha impulsado un proceso intensivo de renacionalización forzada de la ciudadanía. No era ésta la única posibilidad que se abría con la recuperación de la democracia y del régimen autonómico, pero ha sido la desarrollada en estos últimos treinta y cinco años con diferentes intensidades.

Tras la segunda dictadura, el objetivo de dotar de autonomía a Cataluña en 1975 era compartido por todas las fuerzas democráticas españolas. No cabía ninguna duda que la nueva etapa democrática implicaría la recuperación de un autogobierno para Cataluña al menos tan amplio como el que, con distinta intensidad y éxito, había existido durante la República (1931-1939). En un proceso sobradamente conocido de diálogo y negociación ${ }^{18}$, la Constitución española de 1978 definió a nuestro país como un Estado social y democrático de derecho que aspiraba a ser una sociedad democrática avanzada y que se configuraba como un Estado compuesto autonómico que podríamos llamar de corte federalizante, aunque no genuinamente federal, pues le faltan algunas características de este modelo, en concreto los cuatro siguientes: coparticipación decisoria en las reformas constitucionales, las comunidades autónomas no son soberanas ${ }^{19}$, el poder constituyente es unitario y conserva exclusivamente el poder de reforma constitucional, ante el que las comunidades autónomas sólo tienen una facultad de iniciativa y, en cuarto y último lugar, en nuestro sistema constitucional un Estatuto de autonomía es una norma infra-constitucional, jerárquicamente subordinada a la única Constitución estatal (CE 147.1 y CE 147.2-d, CE 167, CE 168, CE 161.1-a y Ley orgánica del Tribunal constitucional (LOTC), 27.2-a, pues "el único parámetro para enjuiciar la

${ }^{18}$ Cfr. J. A. González Casanova (2014) Cataluña, federación o independencia. Cuarenta años de federalismo socialista catalán, Lérida, Milenio, 192, especialmente pp. 3-86.

19 STC 4/1981, de 2-II, fund. 2, y STC 100/1984 de 8-XI, fund. 3). 
validez constitucional de una disposición incluida en un Estatuto de Autonomía es la propia Constitución", según la STC 99/1986 de 11-VII, fund. 4).

Para explicar lo que hemos llamado "proceso intensivo de renacionalización forzada" podríamos esbozar una lectura crítica de la reciente historia de Cataluña en relación con España en cuatro períodos: 1977-1980, 1980-2003, 2003-2006 y 2006-2015. La sucesión de estas fases diferenciadas puede explicar someramente la situación a la que hemos llegado en 2015.

El primer período (1977-1980) desde la recuperación democrática, que representaron las elecciones parlamentarias de 15 de junio de 1977 está caracterizado por una lucha conjunta y unitaria de todas las fuerzas democráticas españolas en defensa de la autonomía de al menos algunas de las comunidades históricas; es cierto que las posiciones desde antiguo eran diferentes y aún enfrentadas, pero por encima de esa diferencias latentes, algo común caracterizó esta etapa: el objetivo de la recuperación de instituciones de autogobierno para Cataluña, el País Vasco y Galicia, y en alguna medida también para Andalucía, recuperación que era una demanda compartida por las fuerzas políticas de todo el espectro de parte del centro cuyo origen se situaba en la oposición democrática a la dictadura y de toda la izquierda. En este periodo ante los hechos nacionales diferenciales existió un mayor pluralismo, cierta "porosidad" y bastante ambigüedad o confusión en el conjunto de las fuerzas democráticas.

El segundo período (1980-2003) podríamos considerarlo como el de la "nacionalización" de algunos aparatos de la autonomía, especialmente a través de los medios de comunicación, la formación de un funcionariado de mentalidad u "obediencia" nacionalista y la "nacionalización" de la educación escolar, especialmente la primaria y la secundaria, políticas seguidas todos ellas por los sucesivos gobiernos autonómicos presididos por Jordi Pujol, alimentada con una permanente confrontación nacionalista, aunque casi siempre de "baja intensidad".

El tercer período (2003-2006) ha sido de búsqueda de una nueva relación jurídico-política pactada, entre las fuerzas políticas catalanas (todas, excepto el Partido Popular, aunque en un primer momento en el partido liderado por Josep Piqué también participó en ese intento) y con una parte importante del espectro de fuerzas parlamentarias españolas, durante el gobierno "catalanista de izquierda" presidido por Pasqual Maragall.

El cuarto período (2006-2016), en el que aún nos encontramos, es el de la reanudación de la confrontación nacionalista, al principio bajo el segundo gobierno 
de coalición entre PSC-PSOE, ICV-EUiA y ERC, presidido por el también socialista Montilla, pero dependiente y condicionado por ERC, de los gobiernos de Artur Mas y de Carles Puigdemont, con un cierto afianzamiento electoral y mediático del independentismo, aunque con un progresivo descenso de los sufragios conseguidos por las fuerzas abiertamente independentistas. Este periodo propiamente se inició en el momento de la aprobación del Estatuto de 2006, rechazado tanto por ERC como por el PP, cuyos 99 diputados interpusieron recurso de inconstitucionalidad parcial ${ }^{20}$, partido que llevaba casi dos años creando en toda España un clima de tensión y haciendo campaña contra el Estatuto pidiendo, como se hizo tristemente popular, "una firmita contra los catalanes". Ambas fuerzas ${ }^{21}$ pidieron el "no" en el referéndum al que el 18-VI-2006 se sometió el Estatuto ${ }^{22}$ que obtuvo los siguientes resultados: participación 48,85\% y, por tanto, abstención: $51,15 \%$; votos a favor: 73,90\%; votos en contra: $20,76 \%$; votos en blanco o votos nulos: $5,34 \%$.

La historia posterior al Estatuto de 2006, vigente hoy como Ley orgánica del ordenamiento español y como Ley constitucional de la Generalitat de Cataluña, es bien diferente del proceso que hasta ahora hemos considerado. En realidad durante los treinta y un años que median de 1975 a 2006 asistimos a una labor conjunta de todas las fuerzas democráticas españolas y catalanas para la integración desde la diversidad de Cataluña en España, promoviendo, desarrollando y garantizando un sistema constitucionalizado de autogobierno que ha sido recogido en los Estatutos de 1979 y de 2006. No obstante la sentencia del TC de 28-VI-2010 (STC $31 / 2010$ ) ha supuesto un punto de inflexión en la interpretación de este proceso.

\subsection{Tras la sentencia del Tribunal constitucional, el conflicto de las interpre- taciones}

Tras la citada STC 31 / 2010 retenemos sintéticamente dos posiciones. Los primeros a los que nos referiremos defendieron tras esa sentencia una interpretación restrictiva y victimista de la misma, que lograron hacer pasar por buena: así los defensores

\footnotetext{
${ }^{20}$ Recurso $n^{\circ} 8045 / 2006$, del que fue ponente $M^{a}$ Emilia Casas Baamonde, presidenta del TC.

${ }^{21}$ Tras algunas vacilaciones y un debate, pasando por el voto en blanco y la abstención, ERC pidió el "no", igual que el PP y Ciutadans-Partit de la Ciutadania; en cambio, el "sí" fue solicitado por PSCPSOE, CiU y la coalición de izquierda ecosocialista IC-V y EUiA.
}

${ }^{22}$ Aprobado finalmente por el Senado el 10-V-2006 como Ley orgánica LO 6/2006 de Reforma del Estatuto de Autonomía. 
del "no" de ERC y un sector cada vez más amplio de CiU se unieron objetivamente a los defensores del "no" del PP para bloquear la vigencia y desarrollo de una Ley aprobada por los parlamentos catalán y español y por la ciudadanía de Cataluña en referéndum.

Otros tras la misma sentencia defendieron una interpretación propositiva y creadora de consenso ${ }^{23}$, que hubiese permitido el pleno desarrollo normativo de una ley del Estado español que había de garantizar una autonomía cada vez mayor de Cataluña: de momento, esta posición, al menos como interpretación, está en retirada y casi "desaparecida" del debate.

2.4.1. La que denominamos interpretación restrictiva está bien recogida en un documento oficial del Parlamento catalán cuya su resolución 5/X de 23-I-2013 afirmaba que la mayor parte de las fuerzas políticas y sociales catalanas había impulsado una profundización democrática y unas medidas de transformación del marco político y jurídico, siendo la más reciente la reforma estatuaria de 2005 que había de culminar en el Estatut de Mirabet. Parecía a esa mayoría que aprobó la resolución de la cámara, pues ése era uno de los fundamentos de la resolución del Parlamento de Cataluña citada (5/X, de 23-I-2013), que

las dificultades y negativas por parte de las instituciones del Estado español, entre las que cabe destacar la STC 31/2010, suponen un rechazo radical de la evolución democrática de las voluntades colectivas del pueblo catalán dentro del Estado español y crean las bases para una involución en el autogobierno, que hoy se expresa con total claridad en los aspectos políticos, competenciales, financieros, sociales, culturales y lingüísticos.

El pueblo de Cataluña buscaba formas de superar el bloqueo dentro del Estado español, y entre éstas habría que contar las resoluciones del Parlamento de Cataluña 742/IX de 27-IX-2012 en que éste constataba la necesidad de que el pueblo de Cataluña pudiese determinar libre y democráticamente su futuro colectivo por medio de una consulta y la resolución 5/X de 23-I-2013 de soberanía y del derecho a decidir del pueblo de Cataluña, por la que de acuerdo con la voluntad mayoritaria expresada democráticamente por el pueblo de Cataluña se debía iniciar el proceso para hacer efectivo el ejercicio del derecho a decidir (...) su futuro político.

Dos años más tarde, había unas nuevas elecciones, esta vez denominadas confusamente por los nacionalistas "elecciones plebiscitarias", concepto contradictorio y en sí mismo irreconocible, tanto por la legalidad vigente como por la ciencia política. En esas elecciones se conseguía una participación del 74,95\% del censo electoral con

${ }^{23}$ Cfr. J. A. González Casanova (2014) op. cit., 89-139. 
una mayoría de escaños para las opciones nacionalistas independentistas, aunque no fuese fácil interpretar las alianzas posibles; en votos ciudadanos los claramente independentistas no obtenían mayoría, quedando en un $47,80 \%$ del voto electoral. Estos fueron los resultados: Junts pel Sí (coalición nacionalista independentista de nacionalistas de centro-derecha, de centro-izquierda (ERC) y otros procedentes de otras áreas como antiguos democristianos y antiguos socialistas), 62 escaños y $39,59 \%$ de votos (1.629.000), Ciutadans 25 escaños y 17,8\% de votos (736.000); PSC-PSOE, 16 escaños y 12,72\% de votos (523.000); Catalunya sí que es pot (CSQP, candidatura unitaria de izquierda eco-socialista y de otros movimientos cívico-sociales), 11 escaños y 8,94\% de votos (368.000); PP, 11 escaños y 8,49\% votos (349.000) y Candidatura d'Unitat Popular - Crida constituent (CUP-CC, de la izquierda radical y de movimientos sociales y alternativos), 10 escaños y 8,21\% de votos (338.000).

El 9-XI-2015, el Parlamento catalán aprobó por 72 votos a favor (los de Junts pel Sí y los de CUP) -y 63 en contra-, como consecuencia de los resultados electorales del 27-IX-2015, una declaración solemne para iniciar la creación de un Estado catalán independiente en forma de república, abriendo un proceso constituyente ciudadano, participativo, abierto, integrador y activo para preparar las bases de la futura constitución catalana.

De esta forma el entonces futuro gobierno catalán, en ese momento pendiente de constitución, quedaba instado para adoptar las medidas necesarias para la efectividad de esta declaración, entre ellas las tres leyes del proceso constituyente, de la seguridad social y de la hacienda pública, que permitiesen que, en ejercicio de la soberanía del Parlamento, el proceso de "desconexión" democrática del Estado español no estuviese supeditado a las instituciones del Estado español -"en particular del Tribunal Constitucional", al que consideraba carente de legitimidad y de competencia tras la STC 31/2010 de 28-VI sobre el Estatuto que el pueblo de Cataluña había votado en referéndum en 2005.

Según la citada resolución de 9-XI-2015, el parlamento catalán iniciaba, al menos verbalmente, un proceso llamado de "desconexión del Estado español", de manera democrática, masiva, sostenida y pacífica para permitir el "empoderamiento" ("I'apoderament") de la ciudadanía de Catalunya y declaraba solemnemente el inicio del proceso de creación de un Estado catalán independiente y republicano.

El 7-IV-2016 el Parlamento de Cataluña reiteró los objetivos básicos de la citada declaración de 9-XI-2015 por 71 votos a favor y 52 en contra, excepto en dos puntos que fueron rechazados, aquéllos propuestos únicamente por la Candidatura 
d'unitat popular (CUP) que llamaba a los cargos electos a desatender las peticiones de las instituciones del Estado y reclamaba que la policía autonómica no ejecutase las órdenes de la Audiencia Nacional.

2.4.2. Presentamos a continuación un par de interpretaciones propositivas y facilitadoras de un consenso que, sin ocultar problemas y recortes y con matices significativos que las diferencian, abrían posibilidades de pacto en sendos artículos de prensa escritos por protagonistas del proceso político reciente.

a) A los pocos días de la citada STC 31/2010, un importante artículo firmado por la ex ministra Carme Chacón, diputada por Barcelona, y por el ex presidente Felipe González, dejaba constancia de otra posible forma de interpretar la tantas veces mencionada STC 31/201024. Era una posición clave que representaba bien la segunda de las posiciones, la lectura posibilista que abría una vía para el consenso. Dejamos constancia a continuación de sus afirmaciones centrales y

${ }^{24}$ Cfr. C. Chacón y F. González (2010) "Apuntes sobre Cataluña y España": El País, 27-VII-2010. Cfr.

J. A. González Casanova (2014) cit., 81-86:

se da la triste circunstancia de que ninguna sentencia del TC ha sido tan mal interpretada nunca como la que recayó sobre el Estatuto catalán. (...) la mayoría fue incapaz de captar o reconocer el verdadero sentido jurídico de una sentencia que estuvo politizada desde el principio por el Partido Popular y, tres años después, por los nacionalista catalanes. (...) La lectura fraudulenta de la sentencia se debió a prejuicios viscerales de todo nacionalismo (el español y el catalán) y al desconocimiento culpable de las reglas lógicas del Derecho. (...) El PP (aseguró) que el fallo le daba la razón. En Cataluña se aceptó esta falsa versión manipulada por el nacionalismo español. Los partidos catalanes, de mayor o menor nacionalismo, hablaron de la ruptura del pacto constitucional con España, pues la sentencia constituía, según ellos, una negación antidemocrática de la voluntad del pueblo de Cataluña que obligaba a reivindicar un Estado propio. // He aquí como una sentencia razonada y razonable jurídicamente provocó un resultado práctico presentado por unos como justo castigo a la soberanía catalana y por otros como justa razón para divorciarse de España. Fue inconcebible tan sectaria exageración. La reiterada frase "indisoluble unidad de España" (...) fue [tan sólo usada] para certificar que Cataluña es una nación y, al mismo tiempo, una parte del Estado. (...) otras cuestiones fundamentales para Cataluña como la inmersión lingüística, símbolos nacionales, derechos históricos, bilateralidad, financiación, fueron aprobadas por la sentencia. Los veintisiete preceptos que se habían de entender cómo los interpretaba el TC no vieron rebajado su contenido. El TC sólo declaró nulos algunos incisos de unos pocos artículos, debido a que, formalmente [en cursiva en el original], no encajaban en la redacción literal de la Constitución... (pp. 81-82).

La STC anuló cinco preceptos sobre el poder judicial de Cataluña, aunque estos remitían a una futura ley que estaba en curso de ser pactada. En definitiva, no había nada trascendental incorregible que impidiese la plena constitucionalidad del Estatuto catalán (p. 83). La única objeción fundada se refería al concepto de Ley de bases y al blindaje que se pretendía (a. 111 del Estatut de Mirabet). El TC defendía la primacía del Gobierno central y consideraba que el TC era el garante de dicha primacía, a la hora de decidir qué es lo básico. 
de sus conclusiones en lo que se refiere a la STC, que fue "ambivalente" según González y Chacón. Por un lado la STC 31/2010 había rechazado casi todas las objeciones del recurso del PP, aunque en los fundamentos de la misma se reflejaba un desconocimiento de la diversidad catalana en la plural realidad española; por otro lado el Estatut de Mirabet (2006) había consagrado el mayor nivel de autogobierno alcanzado por Cataluña en toda su historia y el mayor también entre todos los sujetos políticos de Europa que no son estados, las llamadas "naciones sin Estado". Además la STC reconocía, entre otros, el estatuto lingüístico del catalán, la bilateralidad, el sistema de financiación, los derechos históricos y la organización territorial propios de Cataluña.

La lectura política de ambos políticos socialistas era clara: el triunfo emocional había sido del PP, aunque hubiese fracasado en su recurso, pero no en los efectos que tuvo la larga e interesada campaña de obstrucción contraria a la renovación del TC.

Los dos partidos enteramente contrarios al Estatuto, el PP y la ERC, opuestos desde el primer momento o de forma oportunista tras el pacto entre los presidentes Rodríguez Zapatero y Mas, son los que triunfaron en su estrategia de tensión, enfrentamiento y bloqueo de soluciones. Ésta es la paradoja: un Estatuto vigente ya durante diez años, sin problemas en su aplicación más allá de los "normales" conflictos jurisdiccionales y competenciales, con altas dosis de autogobierno, se ha convertido en el "imaginario" de los que no aceptan una historia común y los que quieren imponer una historia única en el mismo enemigo a rechazar. En esa dialéctica de confrontación, se ha conseguido atraer a una única posición, liderada en este momento por los independentistas de ERC y los actores de la sociedad civil controlados desde esa posición, a amplios sectores centristas, nacionalistas o no tanto, y a parte de sectores de la izquierda.

Parece muy evidente que los efectos jurídicos de la STC fueron pequeños (un solo artículo e incisos a párrafos de 13 artículos sobre 238 fueron declarados inconstitucionales); la práctica totalidad del Estatut de Mirabet sigue en vigor como Ley orgánica del Estado español y como Ley fundamental de Cataluña.

El PP había recurrido el Estatuto porque creía que más de 120 artículos eran inconstitucionales y el TC declaraba tales tan sólo catorce, como ha quedado indicado. Haciéndose eco de esta realidad, Paloma Biglino Campos, catedrática de Derecho constitucional en la Universidad de Valladolid y entonces directora del Centro de Estudios Políticos y Constitucionales, podía declarar que

Cataluña conserva prácticamente intactos los nuevos ámbitos de autogobierno que había alcanzado con la aprobación del Estatuto. Los pocos preceptos declarados inconstitucio- 
nales y los que han sido interpretados conforme a la Constitución no cuestionan por lo general previsiones que contradigan disposiciones materiales de la norma fundamental. ${ }^{25}$

Aunque por unos y otros se haya ocultado cuidadosamente, lo cierto es que el TC validó todos los perfiles competenciales y los elementos estructurales del Estatuto de 2006 y rechazó de plano el recurso del PP.

b) El segundo artículo era de Carles Viver-Pi Sunyer, inspirador del "núcleo duro" del Estatut de Mirabet, catedrático de Derecho constitucional y anterior vicepresidente del TC, en resumen un buen conocedor del Estatuto y de la jurisprudencia constitucional, que antes de la STC 31/2010 había escrito:

La segunda generación de estatutos ha establecido unas bases sólidas para mejorar de forma importante el autogobierno de comunidades autónomas, pero su cumplimiento requiere que el Estado modifique algunas políticas normativas muy arraigadas que no concuerdan con las previsiones estatutarias y que es preciso adaptar a las exigencias de los nuevos estatutos para hacerlos plenamente eficaces. ${ }^{26}$

Unas semanas más tarde de la STC 31/2010, Carles Viver escribía, sin excesivos tecnicismos, unas pocas cuartillas para evaluar los efectos jurídicos de la STC $31 / 2010$, aunque sin poder entrar en todos los matices, tan importantes en estos casos. Su valoración, obligada "por deber cívico", evitaba conclusiones políticas y críticas técnico-jurídicas de la sentencia. ${ }^{27}$ La posición de Viver era, en lo que se refiere a nuestra exposición, bastante similar a la anteriormente expuesta por Chacón y González, aunque más analítica y precisa en las previsiones de las consecuencias negativas de la STC 31/2010. Lo esencial de ésta podría resumirse como sigue:

${ }^{25}$ Cfr. J. A. González Casanova (2014) op. cit., 85. Pueden verse entre otros los siguientes artículos de esta autora sobre la cuestión: "Un complejo modelo de distribución de competencias que necesita otras garantías: Revista de administración pública, n. 187 (2012) 11-29; "La reforma de los Estatutos de Autonomía: un problema que se desplaza, otro que se agudiza y otros por resolver": Corts: Anuario de derecho parlamentario, n. 25 (2011) 19-35; "La Constitución fue norma por ser pacto federal": Teoría y realidad constitucional, n. 28 (2011) 179-204; "Reforma de la Constitución, reforma de los Estatutos de Autonomía y configuración constitucional del Orden de Competencias": Revista de las Cortes Generales, n. 65 (2005) 7-30; "La lealtad constitucional en el Estado de las Autonomías": Revista jurídica de Castilla y León, n. 1 (2004), extra, dedicado a los 25 años de Constitución, 51-74, y "Los espejismos de la tabla de derechos" en V. Ferreres Comella, P. Biglino Campos y M. Carrillo (2006) Derechos, deberes y principios en el nuevo Estatuto de Autonomía de Cataluña, Madrid, Centro de Estudios Políticos y Constitucionales, 62 (concretamente, 39-61).

${ }^{26}$ Cfr. J. A. González Casanova (2014) op. cit., 86.

27 C. Viver PI-Sunyer (2010) "Efectos jurídicos de la sentencia del Estatut": El País, 20-VII-2010. 
1. Desde una perspectiva jurídica la Constitución sólo admite la Nación ${ }^{28}$ española; por tanto no se pueden aplicar a Cataluña los términos nación y realidad nacional en la misma perspectiva jurídica ${ }^{29}$. No se declara formalmente la inconstitucionalidad de esos incisos en el preámbulo pues no tienen efectos interpretativos respecto del resto de artículos; cuando se usa "nacional", este adjetivo se refiere a "nacionalidad".

2. Las referencias al "pueblo catalán" como origen del poder, a la "ciudadanía catalana" y a los "derechos históricos" son constitucionales, pero no deben interpretarse para fundamentar del poder de la Generalitat al margen de la Constitución; se cierra cualquier posible interpretación expansiva implícita en la referencia a los derechos históricos.

3. La sentencia deja intacta la regulación del catalán en el ámbito de la enseñanza y su carácter de lengua vehicular preferente, aunque no única, por lo que las administraciones catalanas y sus medios de comunicación no pueden imponer su uso preferente; el Estatuto admite que el legislador ordinario pueda dar ese trato preferente a cualquiera de las dos lenguas oficiales para corregir situaciones históricas de desequilibrio ${ }^{30}$.

${ }^{28}$ Con mayúscula en el original.

${ }^{29}$ Éste y las demás palabras en cursivas del artículo no son del original.

${ }^{30}$ El citado artículo de F. GONZÁlEZ y C. CHACÓN añade: Más allá de las críticas que pudiera merecer ese planteamiento, en la práctica no va a exigir ningún cambio significativo, aunque puede ser un semillero de conflictos. También respecto a la lengua se reconoce el deber general de conocer el catalán. Aquí se rompe clamorosamente la igualdad entre las lenguas oficiales que según la propia sentencia debería presidir la regulación estatutaria. Esto significa que si un ciudadano alega desconocimiento del catalán, las comunicaciones que los poderes públicos le dirijan en esta lengua carecen de efectos y además, añade la sentencia, no puede imponérsele la obligación de pedir a la Administración que le dirija las comunicaciones en castellano. Esto parecería llevar a la exigencia de que todas las comunicaciones fueran bilingües; sin embargo, la sentencia afirma que pueden hacerse en una única lengua siempre que se arbitren "mecanismos" para que quienes prefieren la comunicación en castellano puedan obtenerla sin que el mecanismo para conseguirlo les suponga una carga. Aquí deberá verse qué se entiende por carga en este contexto y deberá ponerse imaginación para hacer compatible el uso del catalán con la ausencia de cargas individuales. Por último, el legislador que regule la obligación de empresas y establecimientos de atender en cualquiera de las dos lenguas, según parece decir la sentencia, deberá hacerlo en función de los tipos de establecimiento -no es lo mismo una gran empresa que una empresa familiar-y sin exigir que todos los dependientes hablen las dos lenguas. Igualmente, parece reconocer la constitucionalidad del derecho a dirigirse en catalán a los órganos constitucionales del Estado y a los Tribunales Constitucional y Supremo, aunque corresponde al legislador estatal concretar su alcance y contenido. 
4. El carácter vinculante de los dictámenes del Consejo de Garantías relacionados con los derechos estatutarios y la exclusividad de la función supervisora del Síndic de Greuges en relación con la Administración autonómica son cuestionados.

5. Contra lo que parecía ser también la opinión general, la STC $31 / 2010$ admite que los Estatutos puedan contener preceptos en los que se haga referencia a cuestiones relativas a las competencias de los órganos judiciales.

6. Ninguno de los preceptos relativos a la acción exterior de la Generalidad mereció ser declarado inconstitucional, con una excepción, el referido a los mandatos dirigidos al legislador estatal que quedaron reducidos a recomendaciones (la pérdida es significativa).

7. La sentencia salva en apariencia la exclusividad de la Generalitat en sus competencias, pero ésta no puede impedir que el Estado intervenga en esos ámbitos declarados exclusivos. Aquí está una de las claves de toda la sentencia y se producen los efectos más negativos, pues se altera la jurisprudencia anterior al declarar que los Estatutos no pueden contribuir a delimitar el contenido y alcance de las competencias, ni estatales ni autonómicas, pues esto corresponde en exclusiva a la CE y al TC.

8. La sentencia degrada la función constitucional de los Estatutos como normas integradas en el bloque de constitucionalidad y acota el alcance de las leyes de bases estatales, etc. con el grado que considere conveniente.

9. La STC desactiva prácticamente todas las novedades en las definiciones de competencias concretas de la Generalitat (60 artículos). La situación tras la sentencia será la misma que existía antes de aprobarse el nuevo Estatut: la delimitación de las competencias en la práctica sigue estando a la libre disposición del legislador estatal ordinario con el control del TC y el único parámetro del texto abierto de la Constitución.

10. Con el sistema de financiación sucede algo parecido a las competencias: la STC declara que los porcentajes que corresponden a la Generalitat en cada uno de los impuestos cedidos hasta las inversiones en infraestructuras no vinculan al legislador estatal. 


\section{La perspectiva jurídica}

En la disputa política y jurídica entre Cataluña y España y en el debate de la revisión constitucional, el ordenamiento jurídico constituye un sistema unitario compuesto de principios y normas jurídicas que conforman y aseguran el orden social en el marco de una organización dada de la sociedad. La sociedad, como base real de la que deriva la existencia del derecho, el orden, como fin al que tiende el derecho, y la organización, como medio para realizar el orden, son los clásicos elementos constitutivos del concepto de derecho, que es producto de la vida social ${ }^{31}$ (ubi societas, ibi ius).

En las sociedades contemporáneas caracterizadas por la complejidad organizativa y la aceleración de los cambios en todos los ámbitos sociales, humanos, sociales, culturales, ideológicos, económicos, tecnológicos, etc., la moderna teoría del derecho como sistema unitario del ordenamiento jurídico, y no solo como conjunto de normas positivas, ha merecido un amplio reconocimiento. La inteligencia del derecho -y particularmente tanto más si se toma como referencia el ordenamiento constitucional- como categoría abierta y dispuesta al siempre mayor desarrollo y garantía de la libertad, la justicia, la igualdad y el pluralismo político democrático como valores superiores del ordenamiento jurídico del Estado. Esto supone que ni siquiera el ordenamiento constitucional puede ser interpretado como fruto de la cristalización definitiva de la voluntad soberana del pueblo, esto es, de la comunidad política constituyente de la Carta magna. Las reformas constitucionales acumulan una ya más que bicentenaria historia constitucional, y de hecho su previsión forma parte de todas las constituciones.

Es obvio que el derecho no es un producto normativo ahistórico, sino más bien lo contrario. De aquí que cuando, en función de los cambios sociales o políticos, una parte relevante de la comunidad política exija reformar el acuerdo político que sustenta el ordenamiento constitucional, la virtud democrática aconseja no ofrecer resistencias persistentes e irrazonables para afrontar la deliberación agregativa de toda la sociedad sobre la reforma constitucional, so pena de resquebrajar la convivencia y, acaso, la paz social.

Esto no significa en absoluto dejar de reconocer la centralidad del principio de legalidad (CE art.9.1). Antes bien, se trata de distinguir bien entre la fuerza o poder coercitivo para aplicar el derecho vigente y el poder normativo para producir

${ }^{31}$ Cfr. S. Romano (1945) L'ordinamento giuridico, Roma. 
el nuevo derecho, ${ }^{32}$ propuesto por una parte de la comunidad política, y sobre el que se debe invitar a todos a deliberar agregativamente para, en su caso, decidir. Este poder normativo (constitucional) es consustancial al valor de la democracia, tanto más inexcusable en una constitución que proclama la voluntad de establecer una sociedad democrática avanzada (CE, preámbulo). Ésta es la mejor vía para asegurar en cada momento histórico el imperio de la ley como expresión de la voluntad popular (CE, preámbulo).

En la disputa jurídica entre Cataluña y España, la importancia política y social del derecho predica de él una doble y compatible función normativa en constante flujo circular: de un lado, la de ser un instrumento de fuerza (poder coercitivo) para garantizar la aplicación de las normas constitucionales vigentes y, de otro, la de constituir una instancia abierta tanto a la reforma de estas como a la creación de otras nuevas (poder normativo). En todo sistema democrático corresponde al ejercicio político acordar el ritmo e intensidad de este flujo de funciones normativas, que van desde la aplicación imperiosa del derecho que es (derecho vigente) a la creación -por reforma o innovación- del derecho que debe ser (reforma constitucional). De ahí la insobornable defensa que merece el ejercicio cordial de la democracia como regla de buena y pacífica convivencia social, y aún más como virtud cívica facilitadora del restablecimiento del consenso constitucional.

\section{I. Historia reciente de una confrontación jurídica y ruptura política: la agenda soberanista catalana y el enfrentamiento institucional}

En la actual agenda soberanista nos encontramos ante un ejemplo de nacionalismo centrífugo -o disgregador- de tercera generación, como otros surgidos a finales del siglo XX y principios del siglo XXI en regiones o naciones subordinadas a otro Estado, que son comunidades (regiones, naciones históricas u otras realidades) que siguen sin estar constituidas en un Estado, con reivindicaciones nacionalistas fuertes, casi siempre un Estado propio, las más de las veces independiente y soberano.

Nuestra Constitución de 1978 dio paso de un Estado unitario fuertemente centralizado a un Estado compuesto, con una gran descentralización que de hecho ha venido a ser un Estado federalizante, aunque no federal "stricto sensu". Como es conocido, el modelo constitucional español no previó un mismo grado de autonomía para todas las comunidades autónomas, nacionalidades o regiones. El relato de

32 N. Bоввіо (1991) Teoría general del Derecho [1958 y 1960] Madrid, Debate, 184 y ss. (hay una edición anterior Bogotá 1983, Temis). 
antecedentes y acontecimientos -ya se trate de resoluciones judiciales, decisiones y reacciones políticas, elecciones autonómicas, movilizaciones sociales, consultas ciudadanas, promulgaciones de leyes o creaciones de nuevas instituciones catalanas, etc.- que jalona las a veces tensas relaciones entre Cataluña y España resulta de notable interés para valorar la gravedad del conflicto político-jurídico planteado y para afrontar el análisis del problema.

Aunque los efectos prácticos inmediatos de la interpretación de la STC 31/2010 fueran escasos, aunque se perdiese el carácter de garantía que ofrecía frente al legislador estatal su incorporación autorizada al Estatuto y aunque éste quedase de hecho supeditado a las leyes estatales, quizá lo más grave para muchos sectores de la opinión pública fue el tono de la sentencia. Para la opinión mayoritaria el Estatuto no se presentó tanto como un pacto entre el Estado y la Generalitat, sino como una norma autonómica que unilateralmente había pretendido imponer bilateralmente obligaciones al Estado, ante lo que el TC pretendía reconducirla como una ley más dentro del bloque de la constitucionalidad, ignorando la peculiaridad del Estatuto de una nacionalidad histórica, aprobado por un parlamento autonómico y refrendado por un pueblo.

Siendo una ley orgánica, un Estatuto de autonomía no es una simple ley orgánica como las otras, una pieza más de la legislación estatal. Un Estatuto, aunque ciertamente fundamenta exclusivamente toda su legitimidad en la CE y sólo en ella, especialmente en el caso de los Estatutos que se elaboraron a partir de la disposición transitoria segunda (y sólo en cierta manera el Estatuto andaluz aprobado al amparo de una interpretación benévola del artículo 151 de la CE), es una ley pactada de las Cortes generales con un parlamento que representa una parte de la soberanía nacional y, por otro lado, una ley refrendada por el sufragio popular. No es una ley más.

Hacer en este momento un recorrido breve sobre lo ocurrido entre junio de 2010 y septiembre de 2015 puede ayudarnos a interpretar mejor y a comprender los procesos de fondo de han acompañado la segunda etapa de desarrolloy aplicación el Estatut de Mirabet (la primera etapa fue 2006-2010). ${ }^{33}$

a) La Sentencia 31/2010 del Tribunal Constitucional de 28-VI-2010, marcó para muchos el punto final de proceso estatutario en Cataluña y la apertura

${ }^{33}$ El precedente resumen se basa en gran parte en la monografía de X. Pons RAfOLs (2015) Cataluña:

Derecho a decidir y Derecho internacional privado, Madrid, Reus. 
del llamado proceso soberanista catalán. Para un nutrido sector de la ciudadanía de Cataluña esta sentencia demostraba la imposibilidad de encontrar un encaje de Cataluña en España al impedir las aspiraciones de autogobierno largamente sentida por buena parte de la sociedad catalana. El Parlamento de Cataluña aprobó el 7 de septiembre de 2010 una Resolución (742/IX) en la que declaraba que Cataluña "debe iniciar una nueva etapa basada en el derecho a decidir". Poco antes, el 10 de julio, una masiva manifestación había recorrido las avenidas de Barcelona bajo el slogan: Som una nació. Nosaltres decidim. Si el proceso soberanista estaba, desde hacía tiempo, latente, con la aludida sentencia y la manifestación ciudadana se aceleró exponencialmente.

b) El 28 de noviembre de 2010 se celebraron elecciones al Parlamento de Cataluña. El partido ganador (aunque sin mayoría absoluta) fue Convergència i Unió que postulaba como eje principal de su programa, acentuadamente nacionalista, la reivindicación de un pacto fiscal.

c) Paralelamente o al margen de los procesos electorales oficiales, los grupos pro-independentistas fueron organizando, sin cobertura legal alguna, consultas sobre la independencia de Cataluña. Hasta finales de 2011 se celebraron consultas soberanistas en 554 de los 947 municipios de Cataluña, incluida la ciudad de Barcelona.

d) En los años siguientes hubo varias manifestaciones importantes: (a) la manifestación multitudinaria del 11-IX-2012,organizada por la Assemblea Nacional Catalana, una entidad de la sociedad civil, y encabezada por el 'slogan' de pancarta decididamente soberanista: Cataluña nuevo Estado de Europa; (b) la del 11-IX-2013, organizada por la misma entidad, que recorrió en forma de cadena humana toda Cataluña de norte a sur, bajo el 'slogan' inequívocamente soberanista Vía catalana hacia la independencia, y la del 11-IX-2014, otra vez masiva que formaba una gigantesca $V$ en dos avenidas de Barcelona (Diagonal, Gran Vía). Hay que advertir, sin embargo, que muchos de estos manifestantes no eran estrictamente independentistas, sino ciudadanos que expresaban sus protestas ante lo que interpretaban la suma continuada de "agravios" de los Gobiernos de España hacia Cataluña. Estas movilizaciones no fueron promovidas ni por los partidos políticos, ni por la Generalitat, sino por entidades $\mathrm{u}$ organizaciones de la sociedad civil que ciertamente contaron con el importante apoyo de los medios de comunicación públicos de Cataluña.

e) El papel claramente propagandístico ejercido por los medios de comunicación fue grande en todas estas movilizaciones sociales. En no pocas ocasiones el 
acento propagandístico se hacía notar en el modo de interpretar el derecho a decidir: éste solo se podía referir a decidir la independencia, y no ya a decidir sobre una posible independencia o sobre fórmulas de encaje de Cataluña en España. De esta manera se intentaba cerrar el paso a una posible interpretación sobre el contenido de la consulta del derecho a decidir en otros términos, tales como el de rechazo a la política del Gobierno de España respecto a Cataluña. Se trataba, así, de reconducir y cristalizar esa interpretación independentista como unívoca e inequívocamente dirigida al rechazo a España como Estado, y no solo a la política del Gobierno de España.

f) Las elecciones al Parlamento de Cataluña, de 25 de noviembre de 2012, en las que la federación Convergència i Unió resultó ganadora-aunque con una apreciable pérdida de escaños quedando lejos de la "mayoría excepcional" solicitada por Artur Mas-condujeron a un pacto entre CiU la federación ganadora y Esquerra Republicana de Catalunya, en el que se establecía que a partir del 31-XII-2013 se debería estar en condiciones de convocar la consulta de acuerdo con el marco legal que la ampare dentro del plazo del año siguiente, a menos que el contexto político y económico requiriese una prórroga. Parece a muchos analistas que dicho pacto político se precipitó ante el fracaso de las conversaciones sobre el denominado pacto fiscal el 20-IX-2012 entre Rajoy y Mas.

g) El Gobierno de la Generalitat, por decreto 113/2013 de 12-II-2013, creó el Consejo asesor para la transición nacional, con el que pretendía "dotarse del mejor asesoramiento jurídico y político" para acometer el proceso soberanista. Este Consejo asesor hizo público, el 26-VII-2013, un primer Informe sobre La consulta sobre el futuro de Cataluña, al que siguieron cuatro más, junto al Libro blanco de la transición nacional de Cataluña. El informe de 2-IV-2015 contiene un balance general de todo el proceso soberanista que se pretende, además, legitimar internacionalmente.

h) El Pacto nacional para el Derecho a decidir (2013) fue otro capítulo más de la agenda soberanista del gobierno de la Generalitat. El Manifiesto sobre dicho Pacto, propuesto por el ex presidente del Parlamento de Cataluña, Joan Rigol, por encargo del presidente Artur Mas, vinculaba el carácter de nación de Cataluña con el derecho a decidir sobre nuestra institucionalización política. Paralelamente se constituyó en el Parlamento de Cataluña una Comisión para el estudio del derecho a decidir de la que debía surgir la propuesta de 
la pregunta o preguntas ${ }^{34}$ y la fecha para la consulta ciudadana, así como el impulso para iniciar el procedimiento de convocatoria del referéndum, cuya fecha se fijó para el 9-XI-2014.

i) El Gobierno de España manifestó su total oposición a dicha consulta por su incompatibilidad con la Constitución y por el carácter unilateral del acuerdo político relativo a la pregunta o preguntas y a la fecha de la consulta. Conviene recordar que ya antes, el 16-I-2014, el Parlamento catalán había aprobado una resolución $(479 / X)$ por la que se acordaba la presentación ante la Mesa del Congreso de los Diputados de una proposición de Ley orgánica de delegación a la Generalitat de la competencia para autorizar, convocar y celebrar un referéndum sobre el futuro político de Catalunya, que no llegó a prosperar en el Congreso de los Diputados, lo que supuso un aumento de la tensión política entre los dos Gobiernos que mantenían rota la comunicación por completo desde hacía meses.

i) La reunión celebrada el 30-VII-2014 entre Rajoy y Mas terminó sin acuerdo político sobre la celebración del referéndum, y unas semanas después, el 26-IX-2014, el Parlamento catalán aprobó la Ley catalana sobre consultas no referendarias y otras formas de participación ciudadana, el mismo día en que Mas firmaba con gran solemnidad el Decreto 129/2014 de convocatoria de una consulta popular no referendaria sobre el futuro político de Catalunya. La reacción de las instituciones del Estado español fue inmediata y contundente: tres días después hubo una reunión urgente del Consejo de ministros que instaba la impugnación de dicha Ley catalana y del Decreto de convocatoria, un sucesivo dictamen del Consejo de Estado y la suspensión de sendas disposiciones catalanas por el TC, alcanzando desde ese momento su máximo nivel la confrontación institucional entre Cataluña y España.

k) Tras un breve paréntesis de calma, el 14-X-2014, apoyándose en las fuerzas independentistas catalanas, Artur Mas presentó una singular propuesta: celebrar el 9 de noviembre un "proceso participativo" al amparo de unos "marcos legales preexistentes" que no se especificaban. La peculiar convocatoria carecía de toda formalización jurídica, así como de las más elementales garantías jurídicas formales con el objeto de evitar así su posible impugnación (sin censo o registro previo, con publicidad en una página web, con una logística asumida

${ }^{34}$ La pregunta fue doble: ¿¿uiere que Cataluña sea un Estado?; ¿Quiere que este Estado sea independiente? Esta doble formulación fue objeto de gran controversia por su complejidad, por limitar el voto a la segunda pregunta, por los problemas de recuento, etc. 
por la Generalitat y con 40.000 voluntarios). Pese a que esta convocatoria carecía de toda formalidad jurídica, el Gobierno español impugnó el proceso participativo que fue suspendido por el Tribunal constitucional el 4-XI-2014. La efectiva celebración de la consulta determinó, finalmente, la intervención de la Fiscalía general del Estado con una querella penal contra el presidente y la vicepresidenta de la Generalitaty la consejera de Educación "por desobediencia y usurpaciones de funciones".

I) En la consulta de 9-XI-2014 se registraron 1.897.274 votos a favor de la independencia, lo que llevaba a una situación de bloqueo del soberanismo, pues éste era el umbral estimado máximo y aun así era insuficiente para seguir hasta el final con la agenda soberanista. Esta parálisis se superó, no obstante, el 14-I-2015 con una reunión de las fuerzas políticas pro-independentistas (Convergència i Unió, Esquerra Republicana de Catalunya y otras organizaciones sociales) en la que se anunció la voluntad política de estas fuerzas de conceder a las elecciones autonómicas, anunciadas para el 27-IX-2015, un carácter plebiscitario imposible jurídica y políticamente sobre la independencia de Cataluña, debiendo ser este el punto único del debate electoral.

Desde las elecciones de 27-IX-2015 los avatares políticos y las luchas partidarias se han sucedido a diario, agravándose la crisis institucional y social en ambos lados con gran daño para la convivencia social. En la actualidad ya no se habla ni se reivindica el derecho a decidir, que hasta ahora había sido el eje central del debate político y de la agenda soberanista, sino antes bien la desconexión de Cataluña del Estado español, la elaboración de una Constitución catalana para un Estado independiente y, finalmente, un referéndum constitucional catalán. ${ }^{35}$

\footnotetext{
${ }^{35}$ En este recorrido no podemos referirnos a una cuestión hoy ampliamente debatida y para muchos superada en la historia de la filosofía política, aunque siga provocando discusiones y equívocos en un debate más que centenario entre posiciones aparentemente irreconciliables en la opinión pública y en el juego político inmediato a propósito de la noción de soberanía. El concepto de soberanía acuñado por Jean Bodin en el siglo XVI y reelaborado como soberanía popular a partir de Emmanuel Joseph Sièyes a finales del siglo XVIII requeriría un análisis cuidadoso y una reflexión crítica imprescindible para aclarar los términos del debate actual sobre una única y excluyente soberanía estatal o una soberanía originaria de una comunidad nacional no estatal. Ya hemos visto los términos en que se expresó la STC 31/2010, a la que nos remitimos.
} 


\subsection{La postergación de la política y la utilización de la confrontación jurídica: limitaciones del derecho y posibilidades de la política}

La relación de Cataluña y España es desde hace tiempo una cuestión territorial disputada y un conflicto básicamente político, requerido de consensos para su solución. Este conflicto político sometido a la lógica legal trata de simplificarse al naturalizarse como estricta cuestión jurídica lo que implica abstraer en gran medida los términos políticos y meta-jurídicos del mismo, los factores históricos, culturales, lingüísticos, sociológicos, económicos, etc., liberando así su densa carga política y remitiendo su solución exclusivamente a las normas jurídicas constitucionales que establecen y regulan la organización del modelo territorial del Estado español vigente desde 1978.

Puede parecer que la decisión política de "juridificar" o judicializar el conflicto entre Cataluña y el Estado español pretende ignorar la intrínseca naturaleza política del mismo, al menos por la pretensión, real o encubierta, de evitar o superar el ejercicio político de búsqueda de consensos pre-jurídicos susceptibles de diseñar o negociar otro modelo territorial del Estado o de encontrar otras fórmulas de encaje de Cataluña en España. Utilizar así el derecho como arma de combate político hace más probable que el enfrentamiento jurídico acabe en una peligrosa estrategia de enfrentamientos políticos "bipolares", planteados y agravados como conflictos jurídicos e institucionales que se suceden en una deriva de ruptura política e institucional entre las partes.

La quebrada curva histórica que con altibajos traza en los últimos decenios la línea de relación de Cataluña y España se precipita en caída y ruptura a partir de la Sentencia 31/2010 del TC de 28-VI, como consecuencia del recurso de inconstitucionalidad presentado por el grupo parlamentario popular, que declaró inconstitucionales ciertas posibles lecturas del preámbulo así como sólo catorce disposiciones del Estatut de Mirabet ${ }^{36}$, al tiempo que formulaba la interpretación conforme a la Constitución de otras tantas de sus disposiciones.

A partir de entonces la cuestión política catalana se complicó mucho más, al traducirse para ambas partes en una combativa cuestión institucional que, desde el Gobierno del Partido Popular, se focalizó y planteó ya de modo exclusivo, pero también inexorable, como cuestión jurídica a costa de la torpe enervación de la

${ }^{36}$ El Estatuto de Autonomía de Cataluña mereció la doble aprobación mayoritaria del Parlamento catalán y de las Cortes generales del Estado español, de conformidad con lo exigido por la Constitución de 1978. 
enjundia y trascendencia política del conflicto. Como respuesta, las instituciones de Cataluña enfrentan un cuestionamiento institucional y jurídico en toda regla, articulado reivindicativamente como proceso soberanista catalán, abanderando un pretendido derecho a decidir tendente a la meta final de un nuevo Estado catalán plenamente independiente del Estado español.

El agravamiento de la situación jurídica sobrevenida con la citada STC 31/2010 se manifestó en el intento de enmascaramiento-o "atrincheramiento"- jurídico del problema, hasta entonces sustancialmente político y social que había estado acotado en los límites de lo pre-jurídico y en ámbitos meta-jurídicos como lo cultural, lo sentimental o lo identitario. Al situarse ya el campo de batalla política en los órganos jurisdiccionales del Estado español el crujido institucional provocado por la aludida sentencia eclosionó con toda gravedad y de modo inevitable al declararse afectado el orden constitucional vigente. Fue la consecuencia directa de la decisión política del grupo parlamentario del PP al reducir la enquistada cuestión política catalana a simple y dura cuestión jurídica, esquivando el diálogo y la búsqueda de acuerdos inherentes al ejercicio político.

El Estatut de Mirabet, un estatuto de los llamados de "segunda generación"37, pretendió superar un simple e imposible mantenimiento del statu quo del modelo territorial de la Constitución de 1978 cuyas disfunciones, frustraciones y, en suma, agotamiento venían ya siendo reconocidas y denunciadas muy ampliamente en España por distintos sectores académicos y creadores de opinión ${ }^{38}$.

El derecho, entendido y aplicado en sentido reduccionista, esto es, como mera legalidad positiva sólo logró que las posiciones independentistas se radicalizaran y las soluciones jurídicas y judiciales fueran abiertamente combatidas y gravemente desobedecidas. Ante un problema sustancialmente político como el catalán, esta interpretación reduccionista de la naturaleza propia del conflicto político a su ulterior expresión jurídica de confrontación -que como entelequia pretende solucionarse con la mera aplicación de las normas vigentes-, revelaba además una pobre y pre-moderna concepción del derecho como mera fuerza

${ }^{37}$ Como también fueron el Estatuto valenciano (Ley Orgánica 1/2006, de 10 de abril, de reforma del Estatuto de Autonomía de la Comunidad Valenciana), el andaluz (Ley Orgánica 2/2007, de 19 de marzo, de reforma del Estatuto de Autonomía para Andalucía) o el aragonés (Ley Orgánica 5/2007, de 20 de abril, de reforma del Estatuto de Autonomía de Aragón).

${ }^{38}$ Vid. al respecto el análisis de autoridad de S. MUÑOZ MACHADO (2012) Informe sobre España. Repensar el Estado o destruirlo, Barcelona, Crítica, 254. A este primer ensayo han seguido, escritos por el mismo autor: (2014) Cataluña y las demás Españas y (2016) Vieja y nueva Constitución. 
coercitiva, privado de su vocación y capacidad de aunar, pacificar y convencer, sin otra arma o virtud que su fuerza coercitiva, ejercitable a costa de su "prestigio" conciliador y, sobre todo, de la alta misión pacificadora y ordenadora de los conflictos políticos y sociales.

Sin verdad o virtud democrática, esto es, sin el concurso precedente del ejercicio político, el derecho vigente carece de legitimidad plena y de la necesaria eficacia ordenadora, pues no basta la mera legalidad formal o procedimental (paradigma legislativo paleo-positivista del Estado de Derecho), ya que la plenitud legitimadora del derecho exige además una legalidad sustancial y democrática, siempre renovada, atenta a los conflictos y los cambios relevantes que se produzcan en la realidad política y social, y en diálogo constante con el cuerpo social (paradigma constitucional neo-positivista). El diálogo y el acuerdo políicos, tan necesarios para la búsqueda del bien común, deben anteceder y acompañar al derecho para que así la legalidad formal vigente no pierda su virtud o sustancia democráticas, ni por tanto su vigor político-social.

Con lo anterior pretendemos señalar que, aun cuando se pretendiese reducir el conflicto entre Cataluña y el Estado español a un mero contencioso jurídico-constitucional, sería preciso estar muy atentos a los modelos teóricos de la ciencia jurídica moderna ${ }^{39}$, que reclama precisamente la función pre-normativa de la acción política "pacticia" para asentar el orden jurídico institucional y social, esto es, como cabal instrumento propiciador de acuerdos pre-jurídicos, fruto de los consensos políticos, que luego a través de procedimientos formales y democráticos integran el ordenamiento jurídico garantizándose así su virtualidad y eficacia.

Es obvio que la primacía del derecho, del todo indiscutible, no obsta, en absoluto, para que haya un precedente y adyacente ejercicio democrático de la acción y el compromiso político, sino que éste legitima aún más plenamente al derecho. Lo jurídico, entendido desde el paradigma paleopositivista no basta, pero lo político no puede prescindir de lo jurídico, aunque esta idea haya calado demasiado en gran parte de la opinión en distintos ámbitos por irresponsabilidad de unos y otros. Como afirma el constitucionalista catalán González Casanova ${ }^{40}$

${ }^{39}$ Cfr. L. Ferrajol (2014) La democracia a través de los derechos, Madrid, Trotta; y también L. FerRajou (2012) "In torno a 'Principia iuris'. Questioni epistemologiche e questioni teoriche", en P. DI LUCIA, editor, Milán.

${ }^{40}$ González Casanova fue uno de los juristas que más influjo tuvieron, a través de los diputados catalanes de la ponencia constitucional (M. Roca Junyent y J. Solé Tura, antiguos militantes como González Casanova del Front Obrer de Catalunya, el FOC, entonces uno de ellos diputado de la minoría catalana 
En el Estado social y democrático de derecho la única garantía de que la política respeta las reglas de convivencia y de que ningún poder, público o privado, se impone antidemocráticamente, son la Constitución y las leyes que no la vulneren. Lo jurídico es lo más político e indiscutible. Cabe su interpretación, su reforma o su derogación, pero, en todo caso, sigue siendo la base del Estado y el TC, su máximo defensor es básico para esa base. Si se pierde autoridad ante los ciudadanos, el Estado y la democracia constitucional se resquebrajan. ${ }^{41}$

En la cuestión catalana, reunir la política y el derecho, una difícil pero inexcusable tarea, está aún pendiente. Si se rehúye el acuerdo político, cabalmente pre-jurídico, y se persiste sólo en la solución jurídica y judicial conforme a la legalidad formal vigente, muy difícilmente se podrá evitar que las instituciones catalanas, a la cabeza de un bien nutrido cuerpo social organizado en movimientos sociales muy activos, se nieguen finalmente, pese al derecho y aún contra el derecho, a desenredar el problema y lleguen a cortar el hilo con el que España y Cataluña han tejido desde el pasado plurisecular su historia común y diversa. Éste es el final previsto en el diseño u "hoja de ruta" del soberanismo catalán.

Entre tanto, Cataluña y España tienen pendiente una serena, amistosa, juiciosa, transparente y sana conversación política para recomponer nuestra historia en común. Así lo exige el bien común. ${ }^{42}$

\section{Análisis de los escenarios actuales}

En el actual momento, primavera de 2016, creemos poder detectar tres posibilidades - escenarios, basados en diferentes análisis de la realidad y de distintas actitudes con bastante apoyo cada una de ellas: rigidez institucional e inmovilismo mental dogmático; herejía emocional y huida hacia adelante; y proposición de posiciones claras sobre las que dialogar, negociar y llegar a pactos. La presentación de estas tres claves nos permitirá pasar en la última parte a una conclusión propositiva que consideramos razonable.

y el otro del PSUC), del entonces diputado y vicesecretario general socialista Alfonso Guerra, miembro de la Comisión constitucional, y del grupo parlamentario socialista catalán (J. Reventós, también "foquero" del FOC), en la redacción de la Constitución y del Estatut de Sau en 1977-1979.

${ }^{41}$ Cfr. J A. González Casanova (2014) op. cit., 80-81.

${ }^{42}$ Cfr. nuestro editorial "La democracia al servicio de todos, integrante del bien común": RFS 70 (2015)

7-28, especialmente pp. 22-27. 


\section{I. Primer escenario: rigidez institucional e inmovilismo mental}

La rigidez institucional, aun siendo una posición jurídicamente impecable, resulta poco realista por no atender en absoluto a un clamor social de cambio que hay en Cataluña, al margen de si este clamor responde o no a una mayoría de la población. En las elecciones autonómicas del 27-IX-2015, el 47\% del censo votó a partidos independentistas, frente a un $53 \%$, que no lo hizo; pero en este $53 \%$ habría una parte significativa que estaría a favor de un referéndum sólo en Cataluña para ejercer el "derecho a decidir". Los porcentajes en el conjunto de la sociedad española son obviamente muy distintos, con una mayoría aplastante en contra de la secesión de Cataluña. El rechazo en su momento por el Congreso de los diputados español de la petición del Parlamento de Cataluña para convocar un referéndum sobre la independencia fue éste: 299 diputados contrarios frente a sólo 47 diputados a favor. La mayoría de los diputados catalanes, en ese momento de los partidos socialista y popular, votó en contra. Por las razones que hemos expuesto de forma extensa en la tercera parte de este editorial, pensamos que ésta no es una solución que permita buscar y encontrar soluciones a la cuestión catalana. España tiene un problema de integración de una parte de su población que se siente maltratada y ajena, y por otro lado la misma institucionalidad constitucional es cuestionada. No queremos repetir los argumentos presentados, tan sólo recordarlos. ${ }^{43}$

La rigidez de las partes en conflicto, el unilateralismo secesionista y los amagos de desobediencia y de ruptura ("desconexión") que son respondidos desde el formalismo jurídico y el inmovilismo mental, sólo alimentan dialécticas de tensión y espirales de violencia verbal, institucional y afectiva. Como tantas veces se ha dicho, hay "separatistas" porque hay "separadores", y viceversa. La firmeza legal, la claridad institucional, la coherencia y lealtad constitucional de unos no están reñidas con la capacidad de escuchar propuestas y de ofrecer negociaciones

${ }^{43} \mathrm{El}$ uso desproporcionado que amplios sectores mediáticos, sobre todo de la capital, han hecho del artículo 155 de la CE está injustificado. Éste no es de "suspensión de la autonomía", como se dice abusivamente, sino de ejecución de la legislación con la garantía del Estado autonómico. En caso de que hubiese un atentado al "interés general" y fuese necesaria la "protección de los derechos de ciudadanía", su aplicación obligaría a hablar entre el Gobierno español y el Gobierno catalán, pero ni es pensable el encarcelamiento de un gobierno o un presidente, ni la disolución de una institución. El presidente de la Generalitat es la más alta representación del Estado en Cataluña. En la mente de los constituyentes quizás estaba muy presente la imagen de octubre de 1934 en la plaza de Sant Jaume y la del gobierno catalán de aquel momento entre las rejas del penal del Puerto de Santa María hasta las elecciones de febrero de 1936. Éste sería un ejemplo de cómo se puede -o no- utilizar el derecho de forma excluyente y agresiva, como "ultima ratio". Cfr. J A. González Casanova (2014) op. cit., 164-166, 117-119 
parciales. Y sobre todo, es posible una mejor labor de pedagogía política, de búsqueda de las verdaderas razones del consenso.

\subsection{Segundo escenario: herejía emocional y huida hacia adelante}

El avance hacia una insurrección secesionista de forma unilateral, la desobediencia, los hechos consumados como las llamadas "embajadas" olas agencias "exclusivas" de la seguridad social o tributaria (las otras ya existen y son plenamente legales y funcionales), los incumplimientos legales y en definitiva el concebido proceso constituyente van configurando para muchos una visión de Cataluña muy alejada de la realidad social catalana, mucho más rica, compleja y variada que esta imagen dominante, este marco mental.

La estrategia independentista actual es débil, pero tozuda y hábil: ¡puede fortalecerse como un ave fénix! El independentismo es débil, pero no está agotado; por otra parte, junto a dos principales actores, las dos burguesías nacionalistas que conforman las "élites extractivas" dueñas del poder mediático-financiero en los entornos del poder político, hay que dejar constancia de la pujanza de un nacionalismo independentista catalán de clase media-baja, y en ese sentido un nacionalismo popular republicano y mesocrático (burgués o menestral), con una fuerte implantación desde el último tercio del siglo XIX, que ha hegemonizado el nacionalismo en algunos períodos, particularmente en el ciclo de la segunda República (1931-1939) y en los últimos años (2003-2015); no hay que ignorar el peso histórico y actual del independentismo, que no está sólo artificialmente alimentado desde el poder, el dinero, la corrupción, el clientelismo,... no sólo, ni tampoco desde la rigidez legalista de los gobiernos centrales y del bloque hegemónico financiero que controla el poder central. Hay también una rigidez rupturista ("herejía emocional") que ha calado en muchos sectores, sobre todo en Cataluña ("no nos quieren" y "no tenemos nada que esperar de Madrid / de España").

Habría que tener en cuenta que los escenarios 4.1 y 4.2 se alimentan mutuamente, y que ciertas posiciones aparentemente equilibradas entre extremos contribuyen a reforzar los extremismos al contaminar algunas propuestas de negociación, en lugar de exigir un discernimiento lúcido e histórico. Hay posiciones indefinidas que contribuyen a la consolidación de la estrategia rupturista al insistir en la "retórica" del diálogo o en la indefinición oportunista y dilación indefinida de procesos, sin tomar decisiones o tomándolas incoherentemente. 
4.3. Tercer escenario: negociación de posiciones con la claridad y la firmeza de los principios constitucionales democráticos, pero con equivalente flexibilidad y mesura

En tiempos de incertidumbre y de indignación no es aconsejable tomar decisiones precipitadas, pero sí hay que usar la sabiduría que proponía Keynes, a quien hemos citado en exergo. Dirigiéndose a las élites financieras londinenses, les avisaba del riesgo de enfermedad del sistema a menos que abracen la sabiduría a tiempo. ${ }^{44}$

¿No hay a veces demasiadas "urgencias"? 2 , ¿no deberíamos aprender la profunda sabiduría que encierran las palabras: el todo es más que la parte, el tiempo más que el espacio?

Los actores políticos y la sociedad civil debemos ser capaces de encontrar aquella lucidez y hacer aquel discernimiento histórico que provoca procesos lentos, pero constantes y seguros que nos hacen avanzar por el buen camino.

Antes de que sea posible vertebrar los sentimientos políticos de los pueblos $-y$ nos parece que en esta coyuntura no lo es- podemos avanzar con el compromiso de lograr acuerdos transitorios que, en su día, puedan madurar en pactos más estables y profundamente compartidos. En primer lugar hemos de lograr el desbloqueo de la situación y para ellos hablemos de lo que ha pasado, aceptar la perplejidad y sin deslegitimar emociones contrapuestas, reconocer que ni los hechos ni los tiempos los habíamos previsto. El actual enquistamiento no es bueno para nadie, para ningún actor político. Aunque no sea evidente para todos que si todos aceptamos algunas pérdidas menores, todos podemos alcanzar logros importantes, ésta nos parece la mejor apuesta.

Si es cierto que en otro momento esta revista se ha definido en favor de una democracia deliberativa ${ }^{45}$, la sabiduría política debería hacernos aceptar que en estos momentos podemos aspirar tan sólo a proponer un modelo agregativo de intereses. El "modelo de agregación" teorizado en su día por Joseph A. Schumpeter ${ }^{46}$ parecía haber sido superado por el modelo deliberativo. Ya no nos bastaba la adición interesada de preferencias a través de partidos políiticos representativos a

\footnotetext{
${ }^{44}$ J. M. KEYNES (1931) The Collected Writings of John Maynard Keynes. Citado.

${ }^{45}$ RFS 70 (2015) 18-19.

${ }^{46}$ Capitalism, Socialism and Democracy, Nueva York 1947.
} 
los que pudiéramos votar de vez en cuando. Esta propuesta sobre la democracia como "agregación" hace que la comprendamos no tanto como un sistema que elabora racionalmente un discurso y una propuesta a partir de la comunicación reconocida de interlocutores iguales (democracia deliberativa según Habermas y Rawls), sino como un sistema que alternativamente acepta o rechaza a unos dirigentes mediante procesos electorales competitivos.

En nuestro momento parece que no podemos esperar una construcción inmediata de objetivos compartidos con valores que tengan significados comunes para todos los actores políticos. Estamos ante la disyuntiva entre el refuerzo del consenso parlamentario en torno al proyecto constitucional y de integración europea o el deslizamiento y la apuesta por un modelo de pluralismo agonístico ${ }^{47}$. Ante esta disyuntiva nos inclinamos por avanzar poco a poco siguiendo un modelo democrático de agregación de intereses, para llegar en su día al modelo democrático cooperativo crítico $^{48}$.

Una cosa es proponer y defender un ideal y otra es reconocer que en una circunstancia determinada puede ser mejor llegar a compromisos prácticos que sumen intereses individuales y corporativos y se negocie desde la claridad y la precisión de las diferentes posiciones de cada actor político. Habermas precisó en su momento que para que haya un auténtico consenso se precisan determinadas situaciones ideales de diálogo y de debate. Nos parece que en la España actual no se dan estas circunstancias. Tampoco el contexto europeo de crisis permite apoyarse en un marco estable y estimulante. El pacto político europeo basado en unos valores cívicos como la solidaridad, la defensa del pluralismo, del bien común u otras virtudes públicas, no dan más de sí. Hemos de contribuir a su regeneración.

Aunque seguimos creyendo que el terreno de lo prepolítico (lo moral, lo cultural, lo antropológico-social y lo espiritual) es el ámbito en que seguir aportando y enterrando esfuerzos, hoy queremos subrayar que de forma inmediata sólo con la apelación al interés y a la necesidad podremos lograr acuerdos que nos permitan desbloquear la situación.

Este tercer escenario, el menos malo para nosotros, debería combinar realismo pragmático desde una concepción agregativa de la democracia ("todos ganan")

${ }^{47}$ Cfr. Ch. Mouffe (2016) La paradoja democrática. El peligro del consenso en la política contemporánea, [The Democratic Paradox, 2000] Barcelona, Gedisa.

${ }^{48}$ RFS 70 (2015) 19-21. 
con la claridad de los principios, la flexibilidad y la previsión en la gestión y la transparencia en todos los procesos, consensuada y aceptada lealmente por todas las partes.

\section{Reflexiones finales: propuesta de un nuevo pacto constitucio- nal para reconstruir una relación entre Cataluña y el conjunto de España}

Un nuevo pacto debe producirse tanto en Cataluña, como entre Cataluña y España; un renovado pacto entre catalanes, entre éstos y el conjunto de los españoles, respondiendo a una búsqueda inteligente y discernida de consenso. Se trata, en suma, de un nuevo pacto que permita el paso de la hegemonía de las posiciones nacionalistas, en los medios de comunicación, en la movilización de masas y en la iniciativa proactiva, a las posiciones pactistas constitucionalistas.

El eje central de esta etapa, para lograr la ratificación en un referéndum político celebrado en toda España y, por tanto, en Cataluña, sería una revisión constitucional para construir un pacto unitario federal (foedus), mejor fundado y más sólido que el anterior. ${ }^{49}$

En un editorial anterior, nuestra revista proponía "una democracia deliberativa, sustancial, con garantías constitucionalizadas, según nuestra mejor tradición europea" 50 . Frente a las llamadas democracias emotivas o competitivas líquidas y a las democracias agregativas o competitivas interesadas, la democracia al servicio del bien común fomenta la cultura de la estabilidad y del pacto, al servicio sobre todo de los intereses comunes de la sociedad.

El proyecto democrático debe articular la complejidad social de las repuestas con la participación deliberativa del pueblo, frente al secuestro de los problemas por las élites o la utilización del sistema en beneficio propio por los populistas. En

\footnotetext{
${ }^{49}$ Algunas disposiciones constitucionales de 1978 (adicional 1 sobre derechos históricos forales; transitoria 2 sobre los territorios que en su momento "plebiscitaron" un Estatuto de autonomía y estaban en una situación de partida diferenciada; y transitoria 4, en la que se prevé la posible confluencia de dos territorios con orígenes y legitimidades diferenciadas) podrían servir para el apoyo de una revisión constitucional de corte federalizante que, de todas formas, sería más deseable que figurase expresamente en las disposiciones de la Constitución revisada para dar fundamento y base sólida.
}

${ }^{50}$ Cfr. "La democracia al servicio de todos, integrante del bien común": RFS 70 (2015) 7-28. 
la raíz de este sistema democrático, deliberativo en las formas y cooperativo en los medios, deben ser complementarios los factores que expresan tanto la fuerza del derecho, como la afirmación de la necesidad creciente de una cultura de la alianza y de la amistad cívica que hagan sostenible a la primera permitiendo su fundamentación continua. Esta cultura de la alianza y de la reciprocidad tiene como referencia la concepción aristotélica de la amistad cívica desarrollada en la Ética a Nicómaco ${ }^{51}$. Las sociedades necesitan, para mantenerse y prosperar, un bien sin el que la vida pública no funciona: la amistad cívica

de los ciudadanos de un Estado que, por pertenecer a él, saben que han de perseguir metas comunes y por eso existe ya un vínculo que les une y les lleva a intentar alcanzar esos objetivos, siempre que se respeten las diferencias legítimas y no haya agravios comparativos. ${ }^{52}$

«Dar espacio» al otro, a los otros ciudadanos con los que se comparten proyectos y metas de ciudadanía, asumir la ascesis del tiempo que falta, de la espera ante los esfuerzos necesarios para lograr y mantener el proyecto, cultivar y ampliar día a día los espacios de comunión, deberían ser señales características de esa democracia deliberativa y cívica en la que caben el reconocimiento, la proximidad y la reciprocidad, de forma que sea cuidada políticamente la amistad cívica.

Esta misión no es sólo de los gobernantes. El cuidado de la democracia no debe ser confiado sólo a las élites mejor preparadas o dispuestas, sino un pueblo capacitado para profundizar en una democracia avanzada. Para ello debemos recuperar, formular y compartir proyectos comunes sobre los que podamos deliberar y que, como pueblo, nos puedan convocar. La educación en general, la investigación y la reflexión en particular, la autoconciencia de la importante responsabilidad social de los partidos políticos y de cada uno de sus componentes, de los medios de comunicación y de los periodistas, de los movimientos sociales y de sus líderes y una específica educación cívica, son medios esenciales para esa regeneración democrática.

Como hemos indicado más arriba, la primera parte de esta transición para superar el enquistamiento bloqueado de posiciones, será la negociación; en un segundo momento, se abrirá paso la búsqueda y obtención de un nuevo pacto posible que responda al gran reto que tenemos delante: articular lo común con lo diferencial. Éste es el gran reto, no lo dudemos. Lo común es bueno para todos, lo singular nos

${ }^{51}$ Libros VIII y IX.

${ }^{52}$ A. CoRtina (2008) "Amistad cívica", en El País, 6-V-2008. 
hace más fuertes, unidos, estables y coherentes en una Europa sometida a grandes desafíos mundiales y a una fuerte crisis institucional y de proyecto integrador ${ }^{53}$.

\section{I. Construimos: un proceso para acordar fines políticos compartidos}

A deliberar se aprende deliberando. Esta deliberación es la que permite un renovado ejercicio del verdadero "derecho a decidir", la autodeterminación social deliberativa y constructiva de la ciudadanía con las siguientes características:

1. Es la hora de un nuevo pactismo. Éste será posible si logramos rehacer una trama cultural compartida y somos capaces de formular objetivos políticos cooperativos críticos. Para ello todos los actores sociales, mediáticos, económicos, universitarios y culturales, incluidas las confesiones religiosas, entre las que obviamente entendemos juega un papel principal la Iglesia católica, deben crear confianza. Para ello muchos actores deben comprometerse en ese gran proyecto: crear confianza en el ámbito plural hispánico. Es éste un gran momento para la sociedad civil de manera que ésta pueda promover ámbitos de escucha y de elaboración de narraciones compartidas. Tenemos una gran historia común y varias historias singulares y valiosas que son patrimonio de todos. Nos tenemos que convencer de esto. Hemos de poder narrar estas historias juntas, hemos de poder reescribir juntos la historia común de España al modo de Europa tras la segunda guerra mundial, y la historia propia de cada una de sus comunidades autónomas (nacionalidades históricas, nacionalidades, regiones,,..$)$.

2. A pactar se aprende pactando y narrando la historia de pactos que atraviesa la historia de Cataluña y la de España. No nacimos sin muchas renuncias, pero sí con muchos ideales, aunque también con grandes dosis de realismo y de idealismo pragmático. También la reciente historia europea nos enseña a saber que es mejor lo que une que lo que divide, que el tiempo es superior al espacio. El papa Francisco ha repetido este principio teológico, pero también filosófico-social, muchas veces, junto a otros principios. No estará de más recordarlos, aunque sea brevemente: afirmar que el tiempo es superior al espacio permite trabajar a largo plazo, sin obsesionarse por resultados inmediatos, iniciar procesos confiando en que el tiempo ilumina y transforma los eslabones

${ }^{53} \mathrm{Al}$ redactar estas líneas, faltan dos meses para el referéndum británico. Al acontecimiento y a las repercusiones del mismo en el proyecto de integración europea dedicaremos un próximo comentario editorial. 
de una cadena en constante crecimiento, sin caminos de retorno. El segundo, la unidad prevalece sobre el conflicto; el tercero, la realidad es más importante que la idea; y el cuarto, que complementa especialmente a nuestro propósito el primero de los citados, el todo es superior a la parte. El símil del modelo del "poliedro" en el que "todas las parcialidades" confluyen pero "conservan su originalidad" puede resultar útil.

3. La búsqueda de consensos y avances en un pluralismo vivido no como amenaza sino como riqueza. Promover y alcanzar un nuevo pactismo en el interior de la sociedad civil de Cataluña, logrando la "reintegración" afectiva y racional de esa minoría relevante formada por entre un $30 \%$ y un $25 \%$ de la ciudadanía que, sin haber tenido posiciones independentistas nunca, ha incrementado un $20 \%$ de ciudadanos claramente independentistas (y, por tanto, secesionistas) que de forma estable han defendido esta posición sin éxito, una posición por lo demás legítima como otras, siempre que se defienda sin violencia ni coacción, aunque no sea la nuestra. Este escenario por el que hay que trabajar, parte de la confianza en el retorno de una parte de la sociedad para configurar el $70 \%-80 \%$ de población favorable al Estado compuesto unitario, sea en su forma autonómica actual, sea en la forma que proponemos de Estado federal compuesto. Siempre habrá un residual independentismo de un máximo del 20\%, y otro pequeño residuo unitario-centralizador: el propósito habría de ser que la suma de ambos no llegase al 30\%. Promover el avance en el pluralismo cultural y el respeto al plurilingüismo en el resto de España formaría parte de esa ampliación del consenso. ${ }^{54}$

\footnotetext{
54 En todo caso, por claridad y por lealtad de todos los actores de este proceso, sería recomendable incluir un "protocolo" neutro para un posible planteamiento de la cuestión de independencia de un territorio, que se podría formular a partir de la STC 42/2014 sobre el "sujeto político" y la capacidad de que el Estado delegue en la Generalitat -que "es Estado"- la realización de una consulta no vinculante. Según la citada sentencia del TC, respecto a las referencias al "derecho a decidir" cabe una interpretación constitucional, puesto que no se proclaman con carácter independiente, o directamente vinculadas al principio primero sobre la declaración de soberanía del pueblo de Cataluña, sino que se incluyen en la parte inicial de la Declaración (en directa relación con la iniciación de un "proceso") y en distintos principios de la Declaración (segundo, tercero, séptimo y noveno, párrafo segundo). Estos principios, como veremos, son adecuados a la Constitución [la letra redonda es de RFS, no del original] y dan cauce a la interpretación de que el "derecho a decidir de los ciudadanos de Cataluña" no aparece proclamado como una manifestación de un derecho a la autodeterminación no reconocido en la Constitución, o como una atribución de soberanía no reconocida en ella, sino como una aspiración política a la que solo puede llegarse mediante un proceso ajustado a la legalidad constitucional con respeto a los principios de "legitimidad democrática", "pluralismo", y "legalidad", expresamente proclamados en la Declaración en estrecha relación con el "derecho a decidir". // Cabe, pues, una interpretación constitucional de las referencias al "derecho a decidir de los ciudadanos de Cataluña", y así debe hacerse constar en el fallo (Fundamento jurídico 3-b).
} 
4. El horizonte europeo puede ser el mejor marco para avanzar en la solución de la cuestión catalana, a corto y a medio plazo. Se trataría no tanto de una solución definitiva o apodíctica, sino de una solución progresiva y constructiva de cesión permanente y creciente de "soberanía" a la UE, con una adecuada intelección del principio dual (doble dirección arriba-abajo) de subsidiaridad (posible recuperación o "devolution" de competencias). Una subsidiaridad bien entendida e interpretada desde los principios de proporcionalidad y atribución, según el Tratado de Lisboa 2009, $\operatorname{art}^{\circ} 5$, podría ofrecer una clave interpretativa esencial para la formulación de las relaciones de soberanía. Este federalismo podríamos recuperarlo, pensarlo y proponerlo desde el patrimonio moral acumulado del movimiento federal europeo (liberales, socialdemócratas, democristianos, republicanos franceses,...).

5. Por último, realizar el trabajo para la hegemonía cultural y moral desde una visión integradora y pluralista en los medios de opinión (medios de comunicación social, redes sociales, iglesias, universidades, deporte, confederaciones empresariales, sindicatos) exige en primer lugar, junto a la creación de ámbitos de confianza, romper en las Españas las "espirales de silencio" sobre nuestra sociedad plural, diversa, plurilingüística, y "desenmascarar" otras visiones sesgadas o falsas sobre la Cataluña explotada, oprimida, "dependiente" (lo que afectivamente funda, aunque no racionalmente, la falacia del "derecho a decidir") o sobre la Cataluña insolidaria y ensimismada, o sobre el conjunto de España atrasado e intolerante, y de este modo cambiar los marcos mentales simplistas.

\subsection{Pactamos: una revisión constitucional para un Estado federal integral y, por ello, asimétrico}

Junto al pacto prepolítico entre todos los ciudadanos de Cataluña y entre los ciudadanos de España y de éstos y los de Cataluña, llegado el momento, que no será inmediato, proponemos la revisión constitucional.

Las apuestas centrales de una propuesta de revisión constituciona ${ }^{55}$ podrían ser las siguientes.

\footnotetext{
55 La CE 168.1 establece: "Cuando se propusiere la revisión (cursiva de RFS) total de la Constitución o una parcial que afecte al título preliminar, al capítulo segundo, sección primera del título I, o al título II (...)". Nos parece más exacto hablar de revisión que de reforma.
} 
A partir de una concepción de España como nación política y como Estado compuesto, en el que existen varias comunidades nacionales históricas, entre ellas Cataluña, el Estado federal resultante de la revisión constitucional sería un:

1. Estado federal asimétrico como modo o forma de articular la diversidad en lo común, especialmente en cuestiones de identidad cultural y de protección lingüística. Esto supone reconocer la realidad social y cultural: la existencia de una España común, pero plural y diversa. Al mismo tiempo podría ayudar a evitar una dinámica centrífuga e inequitativa, derivada de un sentimiento de no sentirse reconocido en su singularidad. Desde esta perspectiva podrían ser de interés:

a) La mención expresa de las Comunidades autónomas, al menos a partir de lo establecido inicialmente en la CE: las históricas y forales, las "plebiscitadas" (Cataluña, Euskadi, Galicia), las que tuvieron acceso a la autonomía a través de CE 151 (Andalucía), las territorialmente especiales (Canarias) y las ciudades autónomas. Todo ello como una forma de reconocer expresamente en la Carta magna tal diversidad.

b) El establecimiento de unas competencias explícitas y tasadas, en cierto sentido "blindadas", para cada uno de los niveles de las administraciones (europea, española, autonómica, local y otras como las insulares, provinciales, etc.), pero no opuesto a "recuperaciones" móviles (principio de subsidiariedad en doble sentido arriba/abajo, como es reconocido por el Tratado de Lisboa).

c) El inicio de un debate profundo y sereno en torno a la forma de integración del poder judicial y la administración de justicia en el marco de un Estado federal como el que se propone. Téngase en cuenta a este respecto que algunas de las instituciones integrantes del poder judicial han sido muy cuestionadas en el proceso de la cuestión catalana desde la aprobación del Estatut de Mirabet (2006). En los Estados federales, al igual que hay un poder ejecutivo y uno legislativo con competencias concretas, también se articula la existencia de dos niveles del poder y la administración de justicia: la federación y cada uno de los estados federados. Deberían pensarse a fondo las cuestiones de la administración de justicia en un Estado compuesto.

d) El avance en la autonomía financiera de las comunidades autónomas, y concretamente de Cataluña. Parece aconsejable que el sistema tienda sobre todo a poner más recursos a disposición de las comunidades autónomas, articulando para ello de forma diversa el principio de autonomía financiera con el principio de solidaridad territorial (CE 156.1), para lo que podría ser una buena senda 
la profundización en el principio que ordene el gasto público en relación con la financiación "per cápita" disponible (ordinalidad "per cápita").

e) La integración de la diversidad territorial en los procesos de toma de decisiones que establecen y regulan lo común. En esta línea, cabría replantear el sentido y las funciones del Senado en cuanto es cámara de representación territorial. Las comunidades autónomas -como Estado que son- deben participar con más intensidad, lealtad y corresponsabilidad en la articulación política y normativa de lo que afecta a todo el Estado.

2. Estado federal integral garante de lo común, que une a ciudadanos y comunidades autónomas en un mismo Estado compuesto, promotor y protector de una forma de articular lo común con lo singular. Desde esta perspectiva debería ser:

a) Garante de la igualdad legal, real y efectiva (CE $1.1 ; 9.2 ; 14$ ) de todos los ciudadanos, en cuanto Estado de derecho y social.

b) Defensor y promotor activo de una auténtica lealtad constitucional de los ciudadanos y de todos los poderes públicos, a partir del "patriotismo constitucional postnacional".

c) Un Estado que valore, proteja y ayude a explicitar lo que nos une desde tiempo atrás, por medio de

1) un sistema educativo con un currículo escolar nuclear (un "core curriculum" en educación primaria y secundaria),

2) una consensuada educación para la ciudadanía común,

3) una visión "negociada" de la historia y de las identidades complejas y, por último, pero no en último lugar,

4) un explícito reconocimiento y protección jurídica de la diversidad curricular;

5) en una palabra, un currículo escolar integrador, que precisamente puede ser común porque integra y reconoce la diversidad (siguiendo el modelo de la "comprehensive school", aunque entendiendo la expresión en un sentido algo diferente).

Proponemos pues un nuevo pacto social y cultural (ideológico, emocional y axiológico) en el ámbito pre-político, entre los ciudadanos de Cataluña, y entre todos 
estos y los ciudadanos de España; este pacto permitirá un nuevo pacto político que sea sometido a un referéndum de revisión constitucional en el que participen todos los españoles.

Uno de los mayores periodistas catalanes del siglo XX, Agustí Calvet, conocido como "Gaziel", escribía en abril de 1923, a propósito de la relación entre España y Cataluña: Una misma y única cosa: incapacidad, incomprensión. Dos muestras distintas, pero gemelas, de un solo caso de iberismo ${ }^{56}$. Creemos que hay otras vías que la incomprensión y la incapacidad, pero hay que buscarlas y construirlas. Para esto hemos escrito este comentario editorial. Puesto que en ningún lugar está dicho que sólo quepa separar o destruir una relación plurisecular, queremos construir en la perspectiva del bien común, de la filosofía social emergente de lo común, un nuevo pacto. Queremos construir y construiremos.

Siguiendo la inspiración de la antigua regla medieval procedente de la tradición justinianea, "quod omnes tangit ab omnibus approbari debet" " $^{2}$, creemos que la búsqueda y promoción del bien común con un discurso integrador de todos y de cada uno, puede ser clave para encontrar una solución a la cuestión catalana, sabiendo que la voluntad democrática que expresa la voluntad de todos (omnes) es una posibilidad mucho más fecunda que el enfrentamiento entre sujetos poseedores de presuntas expresiones de la rousseauniana volonté genérale. Ésta no es la voluntad de todos y de cada uno, la voluntad atenta al bien común, sino una voluntad totalizante y colectiva, desconocedora de las personas y sus comunidades. El pacto (foedus) sí puede fundamentar y garantizar el ejercicio de un discurso integrador al servicio del bien común.

En la construcción de una democracia al servicio de todos, ésta no puede garantizarse solamente a través de estructuras, por muy válidas que éstas sean. Aun siendo no sólo importantes, sino necesarias, incluso las mejores funcionan única-

${ }^{56}$ Ese artículo fue incluido en un libro posterior con un título expresivo, Tot s'ha perdut, escrito tras los hechos de octubre de 1934 con la revuelta de las autoridades de la Generalitat, la efímera independencia de unas horas y la reacción desproporcionada, ejercida tan sólo desde la fuerza, por el Gobierno central republicano conservador.

57 "Lo que a todos atañe todos deben aprobarlo". Cfr. respecto de los reinos hispanos, J. A. MARAVALL (1973) "La corriente democrática medieval en España y la fórmula "quod omnes tangit»", en Estudios de historia del pensamiento español. Edad media, Madrid, Cultura Hispánica, I, 175-190 y con respecto a la historia eclesiástica, cfr. Y. CONGAR (1958) "Quod omnes tangit, ab omnibus tractari et approbari debet": Revue historique de droit français et étranger 36 (4), 210-259. Las referencias en I. MereLLO (2005) "La máxima "Quod omnes tangit". Una aproximación al estado del tema": Revista de Estudios Histórico-Jurídicos 27, 163-175. 
mente cuando existen unas convicciones vivas y unas virtudes cívicas capaces de motivar a los hombres para una adhesión libre al ordenamiento comunitario. La libertad necesita una convicción. La libertad debe ser conquistada para el bien una y otra vez. Si hubiera estructuras que establecieran de manera definitiva una determinada -buena- condición del mundo, se negaría la libertad humana, por lo que, a fin de cuentas, no podrían ser consideradas buenas estructuras. ${ }^{58}$

Esta participación y deliberación deben ir acompañadas, como condición radicalmente necesaria, por una seria y continuada educación para la institucionalidad, para la legalidad y para una democracia de reglas: ésta es una clave democrática esencial. La deliberación democrática está reñida con el espontaneísmo y el emotivismo, y sus posibles derivas populistas. La deliberación democrática promueve y educa en virtudes públicas democráticas, tanto para la reflexión, como para la acción-compromiso.

La intensificación deliberativa del pueblo en la reconstrucción democrática al servicio del bien común y el compromiso ético de todos a través del ejercicio de las virtudes cívicas podrán contribuir a la recuperación de proyectos comunes. Éste puede ser un camino adecuado para promover todo lo que exige el bien común. Este puede ser el camino para reconstruir una democracia al servicio de todos, nunca un sistema sólo al servicio de los intereses particulares. Éste es el servicio del bien común que proponemos, como proclamó abiertamente el Concilio Vaticano Il hace ahora medio siglo:

Promover todo lo que exige el bien común, no anteponer nunca los intereses propios al bien común. ${ }^{59}$

La construcción de una nueva relación y de un nuevo pacto político a partir de un renovado consenso social y cultural de carácter prepolítico es posible. Los ciudadanos de Cataluña pueden y deben construir esta nueva relación en el seno de la propia ciudadanía catalana. Entre ésta y los ciudadanos del conjunto de España es posible reconstruir esa relación pacticia. En la perspectiva de una Europa fuerte, unida, coherente y estable, las asimetrías federales que forman parte del núcleo originario del proyecto de integración europeo, no deberían impedir avanzar en una unidad cada vez mayor y más estrecha. También es posible pensar una España capaz de integrar en lo común lo que es diferente, una España unida, plural

\footnotetext{
${ }^{58}$ BeNEDICTO XVI (2007) Encíclica Spe salvi sobre la esperanza cristiana, 30-XI-2007, n 24.

59 Concilio Vaticano II (1965) Constitución pastoral Gaudium et spes sobre La lglesia en el mundo actual n. 75.
} 
y diversa. La solidaridad entre las comunidades autónomas y la igualdad entre todos los ciudadanos a partir del pacto federal deben incluir el reconocimiento de lo diferencial

Proponemos pues comenzar con un plan de acuerdos pragmáticos de intereses y demandas que en su momento den lugar a un nuevo pacto, social y cultural entre Cataluña y España en su conjunto que dé paso a un nuevo pacto político sometido a referéndum de revisión constitucional, para lograr entre todos hacer posible un discurso integrador. Es nuestra propuesta.

La versión inglesa del editorial, Spain and Catalonia, rebuilding a Pact, está disponible en www.revistadefomentosocial.es desde la aparición en papel de este número. El acceso al texto en castellano es libre desde ese momento en la misma dirección electrónica. 